\title{
Mitochondrial membrane protein mitofusin 2 as a potential therapeutic target for treating free fatty acid-induced hepatic inflammation in dairy cows during early lactation
}

\author{
Jihong Dong, ${ }^{1}$ Gerd Bobe, ${ }^{2}$ ๑ Yuan Guan, ${ }^{3}$ Guojin Li, ${ }^{1}$ Rankun Zuo, ${ }^{4}$ Xin Shu, ${ }^{1}$ Yazhe Wang, ${ }^{1}$ Xudong Sun, ${ }^{1}$ \\ Xiying Chen, ${ }^{1}$ and Xinwei $\mathrm{Li}^{1 *}$ (1) \\ ${ }^{1}$ Key Laboratory of Zoonosis Research, Ministry of Education, College of Veterinary Medicine, Jilin University, 5333 Xi'an Road, \\ Changchun 130062, Jilin, China \\ ${ }^{2}$ Department of Animal and Rangeland Sciences, College of Agriculture and Linus Pauling Institute, Oregon State University, Corvallis 97331 \\ ${ }^{3}$ College of Animal Science, Jilin University, 5333 Xi'an Road, Changchun 130062, Jilin, China \\ ${ }^{4}$ College of Animal Science and Technology, Qingdao Agricultural University, Qingdao 266109, Shandong, China
}

\begin{abstract}
Inflammation is critical in the progression from benign hepatic lipidosis to pathological hepatic steatosis. The objective of this study was to examine the potential role of the outer mitochondrial membrane protein mitofusin 2 (MFN2) in the etiology of hepatic steatosis in dairy cows during early lactation. Using a nested case-control design, we compared blood and liver samples from 10 healthy cows and 10 age-matched cows with moderate fatty liver. Cows with moderate fatty liver had high liver triacylglycerols, elevated plasma concentrations of free fatty acids (FFA) and $\beta$-hydroxybutyrate, and low concentrations of glucose. Cows with moderate fatty liver had overactivated inflammatory pathways in the liver, as indicated by increased abundance of phosphorylated nuclear factor $\kappa \mathrm{B}(\mathrm{NF}-\kappa \mathrm{B}) \mathrm{p} 65$, NLR family pyrin domain containing 3 (NLRP3) and caspase-1 inflammasome protein, and elevated plasma concentrations and hepatic mRNA abundance of their molecular targets IL-1 $\beta$, IL-6, and tumor necrosis factor $\alpha(\mathrm{TNF}-\alpha)$. In the cell culture model, we were able to replicate our findings in cows with moderate fatty liver: $1.2 \mathrm{~m} M$ exogenous FFA decreased the abundance of MFN2 and upregulated phosphorylation levels of

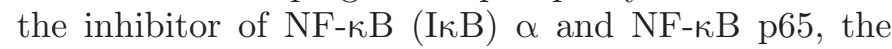
I $\kappa$ B kinase $\beta$ activity, and the abundance of NLRP3, caspase-1, IL-1 $\beta$, IL-6, and TNF- $\alpha$. Whereas MFN2 knockdown potentiated the FFA-induced activation of these inflammatory pathways, overexpression of MFN2 attenuated the detrimental effect of excess exogenous FFA by improving mitochondrial function and decreasing the release of reactive oxygen species, suggesting
\end{abstract}

Received September 26, 2019.

Accepted February 13, 2020.

*Corresponding author: lixinwei100@126.com that MFN2 may be a potential therapeutic target for FFA-induced hepatic inflammation in dairy cows during early lactation.

Key words: dairy cow, moderate fatty liver, mitofusin 2 , inflammation

\section{INTRODUCTION}

Most high-yielding dairy cows experience excessive release of free fatty acids (FFA) from adipose tissue that accumulate in the liver as triacylglycerols (TAG) and inflammation during early lactation (Bobe et al., 2004; Cui et al., 2019). Inflammation is indicated by elevated circulating concentrations of the acute phase proteins serum amyloid A and haptoglobin, and the proinflammatory cytokines IL-1 $\beta$, IL-6, and tumor necrosis factor $\alpha$ (TNF- $\alpha$; Trayhurn and Wood, 2004; German et al., 2010). The nuclear factor $\kappa \mathrm{B}(\mathbf{N F}-\boldsymbol{\kappa} \mathbf{B})$ signal transduction pathway, which also plays an important role in inhibiting insulin signaling, induces proinflammatory cytokine gene expression by phosphorylating the inhibitor of NF- $\kappa \mathrm{B}(\mathbf{I} \boldsymbol{\kappa} \mathbf{B})$ in the cytosol using activated

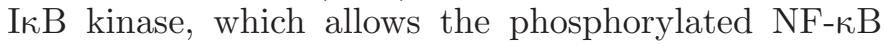
subunit p65 to dissociate, translocate in the nucleus, and induce gene expression of cytokines (Catrysse and van Loo, 2017). Cows with hepatic lipidosis have an

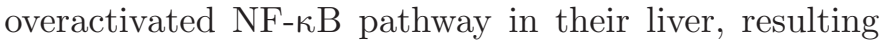
in elevated cytokine secretion and decreased metabolic function (Li et al., 2015). Currently unknown is the effect of bovine hepatic lipidosis on the activation of the NLR family pyrin domain containing 3 (NLRP3) inflammasome signaling pathway, which is activated in mouse and human hepatic lipidosis (Lebeaupin et al., 2015; Yang et al., 2016). Activated NF- $\kappa$ B induces NLRP3 gene expression, which activates IL-1 $\beta$ and IL18 by activating caspase-1 (Kuang et al., 2018).

Mitofusin 2 (MFN2) is an outer mitochondrial membrane protein that participates in mitochondrial 
fusion and respiration, and regulates oxidative metabolism and insulin resistance (Pich et al., 2005; Sebastián et al., 2012). Low abundance of MFN2 decreases mitochondrial function, increases the generation of reactive oxygen species (ROS; Gao et al., 2018), and aggravates altered lipid metabolism (Dong et al., 2019) in the liver of dairy cows, all of which is relevant to various chronic diseases (Filadi et al., 2018). These findings indicate that MFN2 plays an important role in the regulation of hepatic metabolism. We developed a cell culture model for studying bovine hepatic lipidosis by culturing healthy calf hepatocytes at high FFA concentrations, similar to what the liver of the dairy cow experiences during early lactation (Gao et al., 2018; Dong et al., 2019). We first showed that high FFA concentrations decreased mitochondrial function and caused insulin resistance, which could be partly reversed by MFN2 overexpression (Gao et al., 2018). We then showed that high FFA concentrations shifted cellular bioenergetics, decreasing fatty acid $\beta$-oxidation and promoting fatty acid and TAG synthesis, which also could be partly reversed by MFN2 overexpression (Dong et al., 2019). The focus of the current study was the effect of high FFA concentration on inflammatory pathways, specifically hepatic NF- $\kappa$ B and NLRP3 inflammasome pathways. We also evaluated whether MFN2 could act as a potential therapeutic target for FFA-induced hepatic inflammation in dairy cows during early lactation.

\section{MATERIALS AND METHODS}

\section{Cow Study: Moderate Hepatic Lipidosis}

Experimental Design, Animals, and Diets. All experimental procedures and animals handling were approved by the Jilin University Ethics Committee on the Use and Care of Animals (Changchun, China; 2017 clinical trial 201711038). We used a nested case-control design. We tested a total of 130 lactating Holstein cows (parity: median 4, range 2-5; DIM: median 7, range $3-14$ ) to identify fatty liver. Cows were from a 7,000-cow dairy farm located in Changchun City, Jilin Province, China. All cows underwent a routine physical examination by experienced veterinarians to ensure they had no other perinatal diseases, such as hypocalcemia or mastitis. Liver tissue samples were collected via percutaneous biopsy. Cows were classified by measuring TAG content in the liver. Hepatic TAG content in healthy cows was $<1 \%$ liver wt, and in cows with moderate fatty liver was 5 to $10 \%$ liver wt (Bobe et al., 2004). Then, liver and blood samples from 10 cows with moderate fatty liver (FL cows; liver TAG 6-8\% liver wt) were compared with those of 10 age-matched healthy cows from the same farm. A description of cow characteristics at baseline is provided in Table 1 (BW and BCS were measured $1 \mathrm{~d}$ before biopsy; for DMI and milk production, we calculated the average of the last 3 d before biopsy). All cows were fed twice per day at 0830 and $1600 \mathrm{~h}$, and milked twice per day at 0800 and $1530 \mathrm{~h}$. Cows from both groups were housed in tiestall barns and had ad libitum access to the same clean water and diet (Zhao et al., 2015), which was formulated to meet the cows' dietary needs (Supplemental Table S1; https://doi.org/10.3168/jds.2019-17652).

Blood samples were taken via jugular venipuncture on each of the last $3 \mathrm{~d}$ before liver biopsy, between 0630 and $0800 \mathrm{~h}$. Blood samples were immediately centrifuged at $4^{\circ} \mathrm{C}$ for $15 \mathrm{~min}$ at $3,500 \times \mathrm{g}$. The obtained plasma was stored at $-80^{\circ} \mathrm{C}$ until analysis.

Liver tissue samples (approximately $150 \mathrm{mg} / \mathrm{cow}$ ) were collected via percutaneous biopsy according to our previously published standard procedures (Zhu et al., 2019). In short, cows were shaved, sanitized with iodine scrub and $75 \%$ alcohol, and anesthetized with $2 \%$ lidocaine $\mathrm{HCl}$ (Sigma-Aldrich, St. Louis, MO) via subcutaneous injection. Then, a 3 -mm stab incision was made in the skin of the 11 th or 12 th right intercostal space using a scalpel blade. The liver puncture needle

Table 1. Baseline characteristics of healthy cows (liver triacylglycerol $<1 \%$ liver wt) and cows with moderate fatty liver (liver triacylglycerol $6-8 \%$ liver wt; $\mathrm{n}=10$ per group)

\begin{tabular}{lcccccc}
\hline & \multicolumn{2}{c}{ Healthy cows } & & \multicolumn{2}{c}{ Cows with moderate fatty liver } & \\
\cline { 2 - 3 } Characteristic $^{1}$ & Median & IQR $^{2}$ & & Median & IQR & \\
\hline Parity & 5 & $4-5$ & & 5 & $4-5$ & 0.78 \\
DIM & 6 & $4-7$ & & 6 & $5-8$ & 0.67 \\
BW (kg) & 641 & $602-664$ & & 659 & $611-684$ & 0.31 \\
BCS (scale of 1-5) & 3.08 & $2.98-3.22$ & & 3.15 & $3.08-3.31$ & 0.12 \\
DMI (kg/d) & 20.9 & $20.3-21.5$ & & 19.5 & $19.2-20.8$ & 0.03 \\
Milk production $(\mathrm{kg} / \mathrm{d})$ & 32.5 & $29.8-33.2$ & & 29.4 & $28.5-31.5$ & 0.03 \\
\hline
\end{tabular}

${ }^{1}$ For BW and BCS, we took measurements $1 \mathrm{~d}$ before biopsy; for DMI and milk production, we determined the average of the last $3 \mathrm{~d}$ before biopsy.

${ }^{2} \mathrm{IQR}=$ interquartile range. 
(Shanghai Surgical Equipment Factory, Shanghai, China) was inserted into the liver through the intercostal muscle layers. One tissue sample was immediately frozen in liquid nitrogen, and the other tissue sample was immediately fixed with $10 \%$ formaldehyde neutral buffer solution for preparation of tissue slides. To prevent infection, cows were injected with penicillin and streptomycin after the biopsy. Cows in the FL group also received $1 \mathrm{~L}$ of glucose solution $(25 \%)$ by intravenous injection and $200 \mathrm{~mL}$ of propylene glycol, $15 \mathrm{mg}$ of niacin, and $80 \mathrm{mg}$ of choline orally each day for $5 \mathrm{~d}$.

Plasma Analysis. Plasma concentrations of FFA, BHB, and glucose were measured in duplicate using commercially available kits (FFA: FA115; BHB: RB1008; glucose: GL3815; Randox Laboratories, Crumlin, UK) on a Hitachi 7170 autoanalyzer (Hitachi, Tokyo, Japan).

Plasma concentrations of cytokines were measured in duplicate using commercial ELISA kits (IL-1ß: SEA563Bo; IL-6: SEA079Bo; TNF- $\alpha$ : SEA133Bo; USCN Life Science Inc., Wuhan, China) as previously described (Brodzki et al., 2019; Shen et al., 2019). The standard curves for IL-1 $\beta$, IL-6, and TNF- $\alpha$ ELISA were obtained with serial dilutions (IL-1 $\beta$ : 15.6-1,000 $\mathrm{pg} / \mathrm{mL}$; IL-6 and TNF- $\alpha$ : 7.8-500 pg/mL) according to the manufacturer's protocols $\left(\mathrm{R}^{2}>0.99\right.$; http://www .cloud-clone.com/manual/ELISA-Kit-for-Interleukin -1-Beta-(IL1b)-SEA563Bo.pdf; http://www.cloud -clone.com/manual/ELISA-Kit-for-Interleukin-6-(IL6) -SEA079Bo.pdf; http://www.cloud-clone.com/manual/ ELISA-Kit-for-Tumor-Necrosis-Factor-Alpha-(TNFa) -SEA133Bo.pdf). The recovery rates for IL-1 $\beta$, IL-6, and TNF- $\alpha$ ELISA ranged from 90 to $99 \%$. The intraand inter-assay coefficients of variation for IL-1 $\beta$, IL-6, and TNF- $\alpha$ were less than 10 and $12 \%$, respectively (Shen et al., 2019).

Liver Analysis: Determination of TAG Content. Approximately $20 \mathrm{mg}$ of liver tissue was weighed with an electronic scale (Sartorius BSA124S; Sartorius, Beijing, China). The tissue was then homogenized in $5 \%$ Triton-X100, heated in an $85^{\circ} \mathrm{C}$ water bath for 3 min, vortexed, and centrifuged at 2,000 $\times g$ for 5 min at $4^{\circ} \mathrm{C}$. The supernatant was collected, and TAG content was determined using an enzyme kit (E1013; Applygen Technologies Inc., Beijing, China) according to the manufacturer's instructions (Du et al., 2018a). Then, $10 \mu \mathrm{L}$ of supernatant was mixed with $190 \mu \mathrm{L}$ of working reagent and incubated at $37^{\circ} \mathrm{C}$ for $10 \mathrm{~min}$, followed immediately by measurement of absorbance at $570 \mathrm{~nm}$ using a spectrophotometer (Thermo Fisher Scientific, Shanghai, China). Triacylglycerol concentrations are presented in Supplemental Table S2 (https://doi.org/ 10.3168/jds.2019-17652). Each liver tissue sample was analyzed in triplicate.
Liver Analysis: Western Blotting. Protein abun-

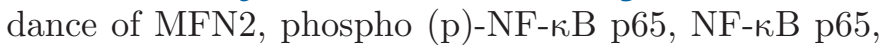
NLRP3, caspase-1, and $\beta$-actin was determined by semiquantitative Western blotting. Protein from liver tissue was isolated using a commercial protein extraction kit that contained a protease inhibitor and phosphatase inhibitor (C510003; Sangon Biotech Co. Ltd., Shanghai, China), according to the manufacturer's instructions (https://www.sangon.com/productImage/ DOC/C510003/C510003_ZH_P.pdf). We determined total protein concentration using a bicinchoninic acid kit (P1511; Applygen Technologies Inc.). Proteins (30 $\mu \mathrm{g}$ ) were mixed with $4 \times$ Protein SDS-PAGE loading buffer and denatured at $95^{\circ} \mathrm{C}$ for $10 \mathrm{~min}$. Then proteins were separated by SDS-PAGE, transferred to $0.45-\mu \mathrm{m}$ polyvinylidene fluoride membranes, and blocked with 3\% BSA/Tris-buffered saline/Tween (TBS-T) buffer solution for $4 \mathrm{~h}$ at room temperature. The blocked membranes were incubated overnight at $4^{\circ} \mathrm{C}$ in TBST containing antibodies to MFN2 (1:1,000; ab56889; Abcam, Cambridge, UK), phosphorylated (p)-NF- $\kappa \mathrm{B}$ p65 (1:2,000; ab86299; Abcam), NF-кB p65 (1:1,000; 4764s; Cell Signaling Technology Inc., Danvers, MA), NLRP3 (1:1,000; ab210491; Abcam), caspase-1 (1:5,000; ab201476; Abcam), and $\beta$-actin $(1: 2,000 ;$ ab8226; Abcam). Next, membranes were washed 3 times and incubated with anti-mouse or anti-rabbit horseradish peroxidase-conjugated secondary antibody (Boster, Wuhan, China) for $45 \mathrm{~min}$ at room temperature.

The blots were visualized using enhanced chemiluminescence solution (Dalian Meilun Biotechnology Co. Ltd., Dalian, China) and digitally captured using a simple protein imager (ProteinSimple, Santa Clara, CA). All protein bands were analyzed using Image-Pro Plus 6.0 (Media Cybernetics, Bethesda, MD) and normalized to that of $\beta$-actin.

Liver Analysis: Quantitative Reverse-Transcription $P C R$. Liver total RNA was isolated using the RNAiso Plus kit (TaKaRa Biotechnology Co. Ltd., Dalian, China). The RNA quality was evaluated by measuring the UV activity ratio at $260 / 280 \mathrm{~nm}$ on a K5500 Micro-Spectrophotometer (Beijing Kaiao Technology Development Ltd., Beijing, China). As an RNA quality cutoff for further analysis, we used a 260/280 $\mathrm{nm}$ ratio of 1.8 to 2.0 , which met the specified purity requirements for all samples. We assessed RNA integrity by visualization of $18 \mathrm{~S}$ and $28 \mathrm{~S}$ ribosomal RNA bands using native agarose gel electrophoresis on a Gel200 loading solution (All-Purpose, Native Agarose; AM8556; Thermo Fisher Scientific, Waltham, MA). The $28 \mathrm{~S}$ ribosomal RNA band was approximately twice the $18 \mathrm{~S}$ band in total RNA samples, indicating that the RNA was intact (Supplemental Figure S1; https:// doi.org/10.3168/jds.2019-17652). The RNA concentra- 
tions were measured at $260 \mathrm{~nm}$. Then, the cDNA was synthesized using a reverse-transcription kit containing random 6-mers and oligo-dT primers (RR047A; TaKaRa Biotechnology Co., Ltd.) according to the manufacturer's instructions (https://www.takarabiomed.com .cn/DownLoad/RR047A.pdf). Quantitative reversetranscription PCR was conducted using the SYBR Green Plus reagent kit (Roche, Basel, Switzerland; Yang et al., 2019) on a 7500 Real-Time PCR System (Applied Biosystems Inc., Waltham, MA). The reaction conditions were as follows: $94^{\circ} \mathrm{C}$ for $2 \mathrm{~min}$, followed by 35 cycles of $94^{\circ} \mathrm{C}$ for $10 \mathrm{~s}, 60^{\circ} \mathrm{C}$ for $15 \mathrm{~s}$, and $72^{\circ} \mathrm{C}$ for $30 \mathrm{~s}$; and finally $72^{\circ} \mathrm{C}$ for 5 min. Each sample was run in triplicate. The $A C T B$ and GAPDH genes were chosen as internal controls (Farke et al., 2008; Zhu et al., 2019; Supplemental Figure S2; https://doi.org/10.3168/jds .2019-17652). The $2^{-\Delta \Delta \mathrm{CT}}$ method was used to calculate mRNA expression data. The primers used for MFN2, $I L 1 B, I L 6, T N F A, A C T B$, and GAPDH were designed using Primer Express software 5.0 (Applied Biosystems) according to National Center for Biotechnology Information bovine reference sequences (Supplemental Table S3; https://doi.org/10.3168/jds.2019-17652).

\section{Hepatic Lipidosis Cell Culture Study}

Calf Hepatocyte Isolation and Culture. Primary hepatocytes were isolated from 5 Holstein calves (age $1 \mathrm{~d}$, female, 30-40 kg, healthy, fasting) using a 2-step perfusion method. The caudate lobe of the liver was obtained by surgical excision according to a previous method (Parker and Gaughan, 1988) after calves were anesthetized and injected with heparin sodium intravenously.

The excised caudate lobe of the liver was immediately rinsed with perfusion solution A $(140 \mathrm{~m} M \mathrm{NaCl}$, $10 \mathrm{~m} M$ HEPES, $6.7 \mathrm{~m} M \mathrm{KCl}, 0.5 \mathrm{~m} M$ EDTA, and 2.5 $\mathrm{m} M$ glucose; $\mathrm{pH} 7.2-7.4,37^{\circ} \mathrm{C}$ ) to remove blood stains on the surface and reveal the blood vessel on the cross section. Next, we perfused the excised caudate lobe with perfusion solution $\mathrm{A}$ at a flow rate of $50 \mathrm{~mL} / \mathrm{min}$ for $12 \mathrm{~min}$, perfusion solution B $(140 \mathrm{~m} M \mathrm{NaCl}, 30$ $\mathrm{m} M$ HEPES, $6.7 \mathrm{mM} \mathrm{KCl}, 5 \mathrm{mM} \mathrm{CaCl}_{2}$, and $2.5 \mathrm{~m} M$ glucose; $\mathrm{pH} 7.2-7.4,37^{\circ} \mathrm{C}$ ) at the same flow rate for 3 min, and perfusion solution $\mathrm{C}(0.1 \mathrm{~g}$ of collagenase IV dissolved in $0.5 \mathrm{~L}$ of perfusion solution $\mathrm{B}$; $\mathrm{pH}$ 7.2-7.4, $37^{\circ} \mathrm{C}$ ) at a flow rate of $20 \mathrm{~mL} / \mathrm{min}$ for approximately 15 to $20 \mathrm{~min}$. Finally, $100 \mathrm{~mL}$ of fetal bovine serum (Hyclone Laboratories, Logan, UT) was used to terminate collagenase digestion.

The perfused caudate lobe was cut into pieces with scissors. The blood vessel, connective tissue, and fat were discarded. The rest of the liver parenchyma was sequentially filtered with $100-(150 \mu \mathrm{m})$ and 200 mesh
$(75 \mu \mathrm{m})$. The hepatocyte suspension was washed twice in RPMI-1640 basic medium (Hyclone Laboratories) and then centrifuged for $5 \mathrm{~min}$ at $500 \times g$ at $4^{\circ} \mathrm{C}$. Cell viability was assessed by staining with trypan blue dye (Sigma-Aldrich). Only cells with a viability $>95 \%$ were used for further testing. A hemocytometer was used for cell enumeration.

Six-well plates were seeded with $2 \mathrm{~mL}$ of hepatocyte suspension $\left(1 \times 10^{6}\right.$ cells $\left./ \mathrm{mL}\right)$ in adherent medium (RPMI 1640 basic medium supplemented with $10 \%$ fetal bovine serum, $1 \mu M$ insulin, $1 \mu M$ dexamethasone, $10 \mu \mathrm{g} / \mathrm{mL}$ vitamin $\mathrm{C}$, and $1 \%$ penicillin/streptomycin). Seeded plates were incubated at $37^{\circ} \mathrm{C}$ under $5 \% \mathrm{CO}_{2}$ for $4 \mathrm{~h}$. After $4 \mathrm{~h}$, the medium was changed to RPMI 1640 basal medium supplemented with $10 \%$ fetal bovine serum and $1 \%$ penicillin/streptomycin and replaced it every $24 \mathrm{~h}$.

Calf Hepatocyte Treatments. In the MFN2 knockdown experiment, calf hepatocytes were assigned to 1 of 5 treatments based on our previously validated and published bovine hepatic lipidosis cell culture model (Gao et al., 2018; Dong et al., 2019): (1) control; (2) si-control [cells were transfected with control of small interfering (si)RNA (GenePharma, Shanghai, China) for $48 \mathrm{~h}$ and incubated with 2\% BSA for $12 \mathrm{~h}$ ]; (3) si-control+FFA (cells were transfected with control of siRNA for $48 \mathrm{~h}$ and treated with $1.2 \mathrm{mM}$ FFA and $2 \%$ BSA for $12 \mathrm{~h}$ ); (4) si-MFN2 [cells were transfected with knockdown of MFN2 siRNA (GenePharma) for $48 \mathrm{~h}$ and incubated with $2 \%$ BSA for $12 \mathrm{~h}$ ]; or (5) siMFN2+FFA (cells were transfected with knockdown of $M F N 2$ siRNA for $48 \mathrm{~h}$ and treated with $1.2 \mathrm{~m} M$ FFA and $2 \% \mathrm{BSA}$ for $12 \mathrm{~h}$ ).

Five microliters of siRNA and $5 \mu \mathrm{L}$ of Lipofectamine 2000 (Invitrogen, Carlsbad, CA) were mixed with 250 $\mu \mathrm{L}$ of Opti-MEM I Reduced Serum Medium (Gibco, Waltham, MA) and incubated for 5 min at room temperature. Then, the mixture was added to each well for $6 \mathrm{~h}$ after $20 \mathrm{~min}$ of incubation at room temperature. The medium was replaced with growth medium for another $42 \mathrm{~h}$. The siRNA sequences are listed in Supplemental Table S4 (https://doi.org/10.3168/jds.2019 -17652). The applied FFA concentration of $1.2 \mathrm{mM}$ was based on our previous studies (Gao et al., 2018; Dong et al., 2019). The fatty acid composition of the stock mix $(52.7 \mathrm{mM})$ was designed to resemble FFA release from adipose tissue solution (Du et al., 2018b; Jia et al., 2019) and contained oleic acid $(22.9 \mathrm{mM})$, linoleic acid $(2.6 \mathrm{mM})$, palmitic acid $(16.8 \mathrm{mM})$, stearic acid (7.6 $\mathrm{m} M)$, and palmitoleic acid (2.8 $\mathrm{m} M$; Sigma-Aldrich). The FFA stock solution was diluted in $0.1 \mathrm{M} \mathrm{KOH}$ at $60^{\circ} \mathrm{C}$, and the $\mathrm{pH}$ was adjusted to 7.4 using $1 \mathrm{M} \mathrm{HCl}$.

In the MFN2 overexpression experiment, calf hepatocytes were assigned to 1 of 5 treatments: (1) con- 
trol; (2) Ad-control [cells were transfected with empty adenovirus (Ad) vector (Hanbio Co. Ltd., Shanghai, China) for $48 \mathrm{~h}$ and incubated with $2 \%$ BSA for 12 h]; (3) Ad-control+FFA (cells were transfected with empty adenovirus vector for $48 \mathrm{~h}$ and treated with 1.2 $\mathrm{m} M \mathrm{FFA}$ and $2 \% \mathrm{BSA}$ for $12 \mathrm{~h}$ ); (4) Ad-MFN2 [cells were transfected with MFN2 overexpression adenovirus (Hanbio Co. Ltd.) for $48 \mathrm{~h}$ and incubated with $2 \% \mathrm{BSA}$ for $12 \mathrm{~h}$ ]; or (5) Ad-MFN2+FFA (cells were transfected with MFN2 overexpression adenovirus and treated with $1.2 \mathrm{mM}$ FFA and $2 \%$ BSA for $12 \mathrm{~h}$ ).

Under the control of the cytomegalovirus promoter, the MFN2 cDNA was cloned by PCR and inserted into HBAD-3*flag-GFP vector (Hanbio Co. Ltd.) for construction of the recombinant adenovirus. To generate the recombinant adenoviruses, HBAD-MFN2-3*flag-GFP and pHBAd-BHG were co-transfected into HEK293 cells using LipoFiter transfection reagent (HB-LF-1000; Hanbio Co. Ltd.). The MFN2 overexpression adenoviruses and empty adenovirus vector were propagated in HEK293 cells and then purified. Then, calf hepatocytes were transfected with adenovirus according to the manufacturer's instructions (Dong et al., 2019; Jia et al., 2019). Briefly, empty adenovirus vectors or MFN2 overexpression adenoviruses were transfected into cells with RPMI 1640 basic medium for $7 \mathrm{~h}$ according to the number of cells $\times$ multiplicity of infection/viral titers. The multiplicity of infection we used in the current study was 50; the viral titers of Ad-GFP were $1.58 \times$ $10^{10} \mathrm{pfu} / \mathrm{mL}$, and the viral titers of Ad-MFN2 were 1.26 $\times 10^{10} \mathrm{pfu} / \mathrm{mL}$. Then, the medium was replaced with growth medium for another $41 \mathrm{~h}$. Both experiments were done in triplicate.

Determination of Calf Hepatocyte I $\kappa$ B Kinase $\boldsymbol{\beta}$ Activity. We used an I $\mathrm{B}$ kinase $\beta$ (IKK $\boldsymbol{\beta}$ ) kinase assay kit (GenMed Scientifics Inc., Wilmington, DE), containing reagents $\mathrm{A}$ to $\mathrm{H}$, to measure the IKK $\beta$ activity. After $48 \mathrm{~h}$ of treatment, cultured hepatocytes were washed twice for 5 min at $300 \times g$ and $4^{\circ} \mathrm{C}$ with ice-cold reagent $\mathrm{A}$, followed by reagent $\mathrm{B}$ in an ice bath for 30 min. Then, the mixture was centrifuged for $5 \mathrm{~min}$ at $16,000 \times g$ at $4^{\circ} \mathrm{C}$. Protein concentrations were measured using a bicinchoninic acid kit (Applygen Technologies Inc.) according to the manufacturer's instructions (http://www.applygen.com/product/danbai/ \%E8\%9B\%8B \% E7\%99\%BD\%E5\%AE\%9A\%E9\%87 $\% 8 \mathrm{~F} / 96 . \mathrm{html})$. Total IKK $\beta$ activity was measured as follows: $130 \mu \mathrm{L}$ of reagent $\mathrm{C}, 20 \mu \mathrm{L}$ of reagent $\mathrm{D}, 20 \mu \mathrm{L}$ of reagent $\mathrm{E}$, and $20 \mu \mathrm{L}$ of reagent $\mathrm{F}$ were mixed and incubated at $30^{\circ} \mathrm{C}$ for $3 \mathrm{~min}$. Then, $10 \mu \mathrm{L}$ of reagent $\mathrm{G}$ or samples were added. Absorbance values at 340 $\mathrm{nm}$ were immediately measured on a spectrophotometer (Thermo Fisher Scientific, Shanghai, China). The non-specific activity of IKK $\beta$ was measured as follows:
$20 \mu \mathrm{L}$ of reagent $\mathrm{C}, 10 \mu \mathrm{L}$ of reagent $\mathrm{H}$, and $10 \mu \mathrm{L}$ of samples were mixed and incubated at $30^{\circ} \mathrm{C}$ for $30 \mathrm{~min}$; then, $100 \mu \mathrm{L}$ of reagent $\mathrm{C}, 20 \mu \mathrm{L}$ of reagent $\mathrm{D}, 20 \mu \mathrm{L}$ of reagent $\mathrm{E}$, and $20 \mu \mathrm{L}$ of reagent $\mathrm{F}$ were mixed and incubated at $30^{\circ} \mathrm{C}$ for $3 \mathrm{~min}$; next, $40 \mu \mathrm{L}$ of pretreatment mixture (mixture of reagent $\mathrm{C}$, reagent $\mathrm{H}$, and samples) was added, followed immediately by measurement of absorbance at $340 \mathrm{~nm}$. The specific activity of IKK $\beta$ was calculated by subtracting the non-specific activity from the total IKK $\beta$ activity.

Calf Hepatocyte Western Blotting. Western blotting was performed as described in the cow study.

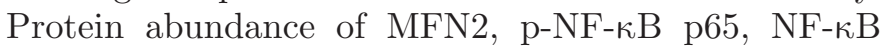

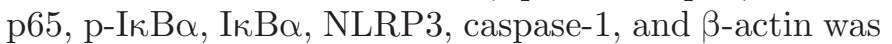
determined by using semiquantitative Western blotting. A commercial protein extraction kit (C510003; Sangon Biotech Co. Ltd.) was used to isolate the total protein from the hepatocytes. The methodology was similar to the cow study, except that membranes were incubated overnight at $4^{\circ} \mathrm{C}$ with antibodies to MFN2 (1:1,000; ab56889; Abcam), p-NF-кB p65 (1:2,000; ab86299; Abcam), NF-кB p65 (1:1,000; 4764s; Cell Sig-

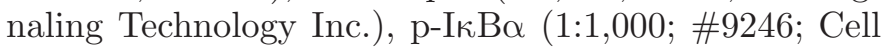

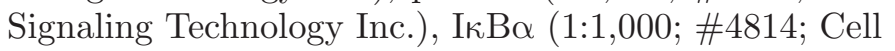
Signaling Technology Inc.), NLRP3 (1:1,000; ab210491; Abcam), caspase-1 (1:5,000; ab201476; Abcam), and $\beta$-actin (1:2,000; ab8226; Abcam).

Calf Hepatocyte Quantitative Reverse-Transcription PCR Assay. Total RNA was isolated from calf hepatocytes using RNAiso Plus (TaKaRa Biotechnology Co., Ltd.). The quantitative reversetranscription PCR assay was performed as described in the cow study.

Determination of Calf Hepatocyte ROS. We used the peroxide-sensitive fluorescent probe $2^{\prime} 7^{\prime}$-dichlorofluorescein diacetate (DCFH-DA; Beyotime Institute of Biotechnology, Jiangsu, China) to measure ROS levels. We incubated the hepatocytes in serumfree medium containing $10 \mu \mathrm{M}$ DCFH-DA at $37^{\circ} \mathrm{C}$ in the dark for $20 \mathrm{~min}$. After washing 3 times with serumfree medium, the fluorescence was detected by flow cytometry (FACSCalibur; Becton Dickinson, Sunnyvale, CA).

\section{Statistical Analysis}

Data were analyzed using SPSS 19.0 software (IBM Corp., Armonk, NY). All data were tested for normality. In the cow study, we compared data from age-matched healthy cows and FL cows using a paired $t$-test. In the calf hepatocyte study, we compared the 5 treatments using a priori contrasts: effect of transfection (si/Ad-control vs. control); effect of high FFA (si/ Ad-control+FFA vs. si/Ad-control); effect of MFN2 
knockdown or overexpression (si/Ad-MFN2 vs. si/ Ad-control); effect of MFN2 knockdown at high FFA (si-MFN2+FFA vs. si-control+FFA); and prevention of the effects of high FFA by MFN2 overexpression (Ad-MFN2+FFA vs. Ad-control+FFA). In the in vivo studies, data were normally distributed and analyzed using paired $t$-tests. In the in vitro studies, we calculated multiple comparisons among groups using 1-way ANOVA, except for the Ad-MFN2 experiment with mRNA MFN2 as an endpoint, because of large group differences. Graphs were created using GraphPad Prism 5.0 (GraphPad Software Inc., La Jolla, CA). Statistical significance was assigned at $P<0.05$. Results are shown as median \pm interquartile range (IQR) or mean \pm standard error of the mean.

\section{RESULTS}

\section{Moderate Hepatic Lipidosis Cow Study}

Using a nested case-control design, cows in both groups were similar in parity (healthy cows: median
5, IQR 4-5; FL cows: median 5, IQR 4-5) and DIM (healthy cows: median 6 , IQR 4-7; FL cows: median 6 , IQR 5-8; Table 1). Body weight and BCS were similar in both groups, but DMI and milk production were lower for FL cows (Table 1).

Liver TAG content was $<1 \%$ of liver weight in healthy cows, and 6 to $8 \%$ of liver weight in FL cows (Figure 1A). Cows with moderate fatty liver had elevated plasma concentrations of FFA (an indicator of excess release of FFA from adipose tissue; Figure 1B) and BHB (an indicator of incomplete $\beta$-oxidation of fatty acids; Figure 1C), and low concentrations of glucose (an indicator of less available glucose to peripheral tissue; Figure 1D). In healthy cows, plasma metabolite concentrations were in the normal range.

Hepatic MFN2 mRNA (Figure 2A) and MFN2 protein (Figure 2B) abundances were lower in FL cows than in healthy cows, by $45 \%$ and $57 \%$, respectively. Inflammatory pathways of NF- $\kappa \mathrm{B}$ were higher in $\mathrm{FL}$ cows than in healthy cows, as indicated by the higher ratio of phosphorylated to unphosphorylated NF- $\kappa \mathrm{B}$

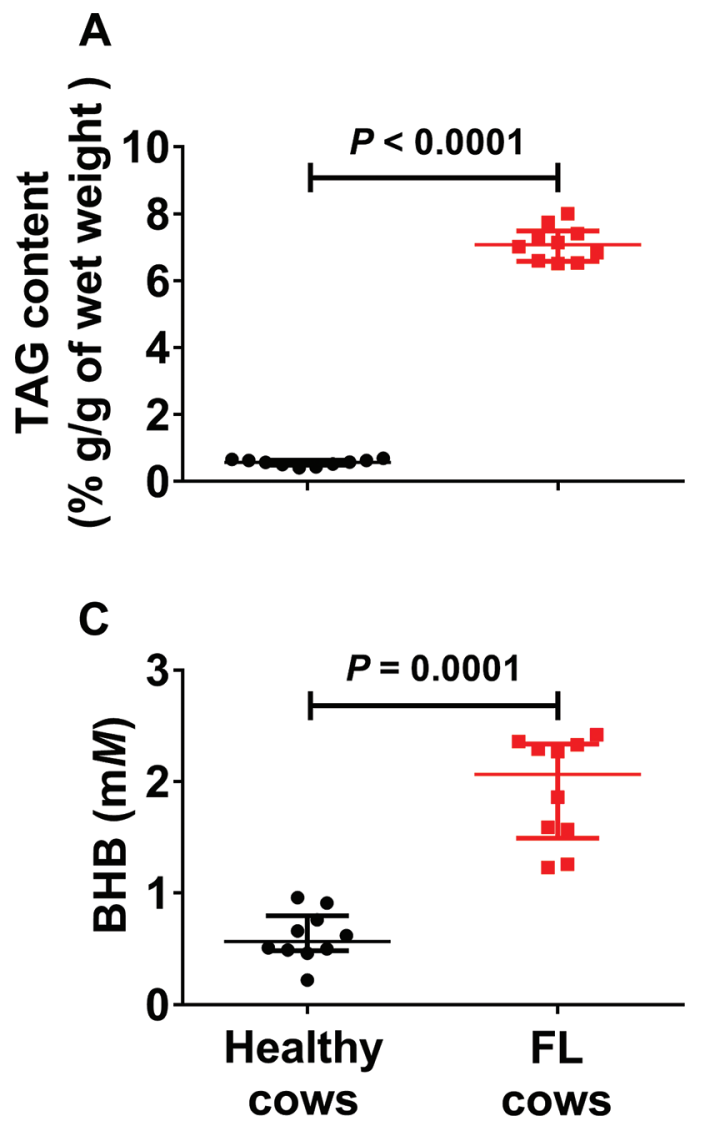

B
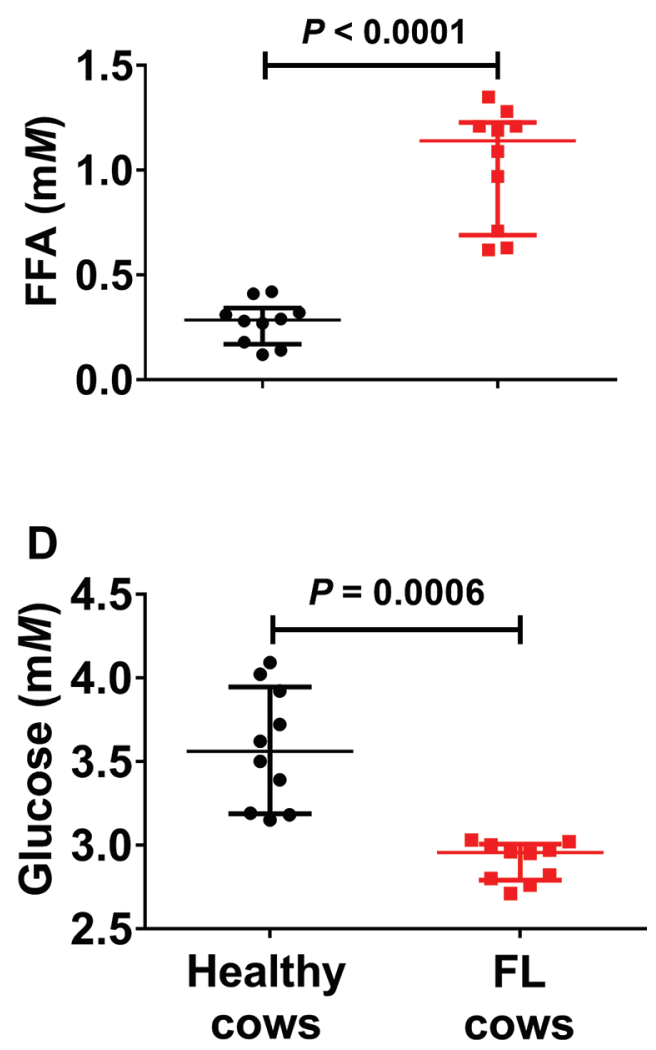

Figure 1. The effect on metabolic profile of moderate fatty liver in dairy cows during early lactation. (A) Hepatic triacylglycerol (TAG) concentrations in healthy cows and cows with moderate fatty liver (FL cows), and plasma concentrations of (B) free fatty acids (FFA), (C) $\mathrm{BHB}$, and (D) glucose in healthy and FL cows $(\mathrm{n}=10$ per group for all measures). Dots represent results for individual cows. Horizontal bars represent median and interquartile range. $P$-values indicate group differences. 


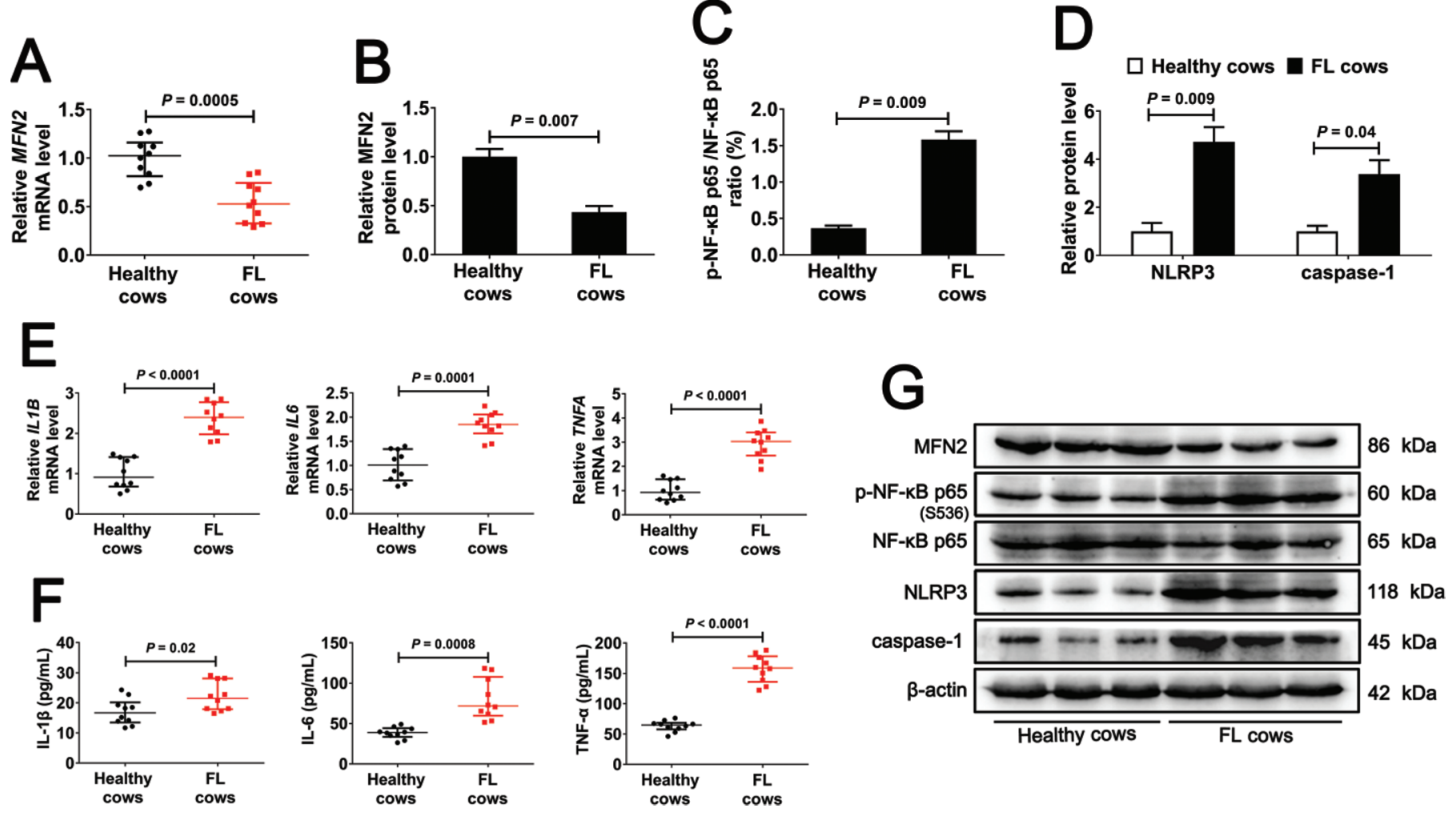

Figure 2. The effect of moderate fatty liver on mitofusion 2 (MFN2) in dairy cows in early lactation, inflammatory pathways in the liver, and inflammatory cytokines in liver and plasma. Relative abundance of (A) MFN2 mRNA and (B) MFN2 protein in healthy cows and cows with moderate fatty liver (FL cows; $n=10$ per group). Inflammatory signaling pathways as indicated by (C) the ratio of phosphorylated to unphosphorylated nuclear factor $\kappa \mathrm{B}$ (p-NF- $\mathrm{BB}$ to NF- $\kappa \mathrm{B}$ ) p65 and (D) the relative abundance of NLR family pyrin domain containing 3 (NLRP3) and caspase-1 inflammasome protein in healthy and FL cows. (E) Relative abundance of mRNA and (F) plasma concentrations of inflammatory cytokines IL1B (IL-1 $\beta)$, IL6 (IL-6), and tumor necrosis factor $\alpha$ (TNFA; TNF- $\alpha$ ) in healthy and FL cows. (G) Representative Western blotting of MFN2, p-NF- $\mathrm{B}$ p65 (S536), NF- $\mathrm{B}$ p65, NLRP3, caspase-1, and $\beta$-actin (standard) in liver. Dots represent results for individual cows. Horizontal bars in A, E, and $\mathrm{F}$ represent median and interquartile range. Results are expressed as mean $\pm \mathrm{SEM}$ in $\mathrm{B}$ to $\mathrm{D}$. $P$-values indicate group differences. For relative abundance, the mean of the healthy cows group was set at 1 .

p65 (Figure 2C). In addition, inflammasome pathways were higher in FL cows than in healthy cows, as indicated by the increased abundance NLRP3 and caspase-1 inflammasome proteins (Figure 2D). As a result, hepatic mRNA abundance (Figure 2E) and plasma concentrations (Figure $2 \mathrm{~F}$ ) of their molecular targets - the inflammatory cytokines IL-1 $\beta$, IL-6, and TNF- $\alpha$ - were elevated in FL cows. In summary, inflammatory pathways were overactivated in FL cows, associated with a low hepatic abundance of the outer mitochondrial membrane protein MFN2. Representative Western blotting is shown in Figure 2G.

\section{Hepatic Lipidosis Cell Culture Study}

Validation of MFN2 Knockdown and Overexpression. Using our previously published cell culture model for bovine hepatic lipidosis (Gao et al., 2018; Dong et al., 2019), we created a successful MFN2 knockdown experiment using siRNA of MFN2 (Figures
$3 \mathrm{~A}-\mathrm{C})$. When we compared si-MFN2 and si-control hepatocytes, we found that the relative abundance of MFN2 decreased (mRNA $-75 \%, P<0.0001$; protein $-64 \%, P<0.0001$; Figures $3 \mathrm{~A}-\mathrm{C}$ ). The same was true in FFA-treated hepatocytes (si-MFN2+FFA vs. sicontrol+FFA) for MFN2 (mRNA $-65 \%, P=0.008$; protein $-73 \%, P<0.0001$; Figures $3 \mathrm{~A}-\mathrm{C}$ ).

Overexpression of MFN2 was successful using adenovirus (Figures 3D-F). When we compared Ad-MFN2 and Ad-control hepatocytes, we found that the relative abundance of MFN2 was increased (mRNA $+63,431 \%$, $P<0.0001$; protein $+173 \%, P<0.0001$; Figures $3 \mathrm{D}-\mathrm{F})$. The same was true in FFA-treated hepatocytes (AdMFN2+FFA vs. Ad-control+FFA) for MFN2 (mRNA $+165,094 \%, P<0.0001$; protein $+261 \%, P<0.0001$; Figures 3D-F).

Effect of High FFA and MFN2 Knockdown and Overexpression on MFN2 Abundance. The addition of $1.2 \mathrm{~m} M$ FFA decreased MFN2 in both the knockdown experiment (si-control+FFA vs. si-control; 

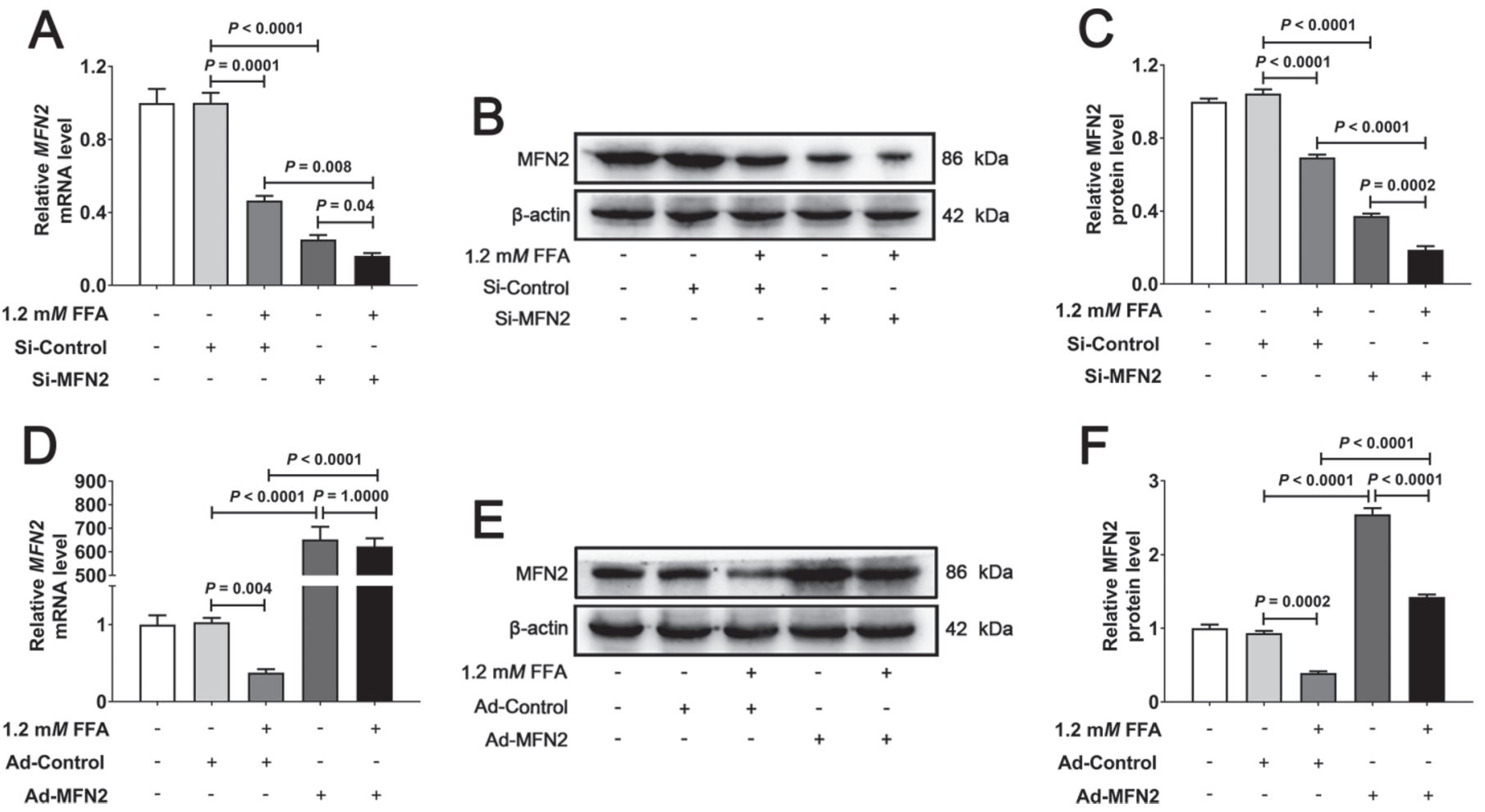

Figure 3. Effect of high free fatty acids (FFA) and mitofusin 2 (MFN2) knockdown and overexpression on MFN2 abundance in calf hepatocytes. (A) Relative mRNA expression of MFN2 in calf hepatocytes. (B) Western blotting analysis of MFN2. (C) Relative protein expression of MFN2. We used the data from the control group to normalize the data for each treatment group. Treatment of si-control had no effect on hepatocytes. Calf hepatocytes were assigned to 1 of 5 treatments: (1) control; (2) si-control [cells were transfected with a control of small interfering (si) RNA for $48 \mathrm{~h}$ and incubated with $2 \%$ BSA for $12 \mathrm{~h}$; (3) si-control+FFA (cells were transfected with a control of siRNA for $48 \mathrm{~h}$ and treated with $1.2 \mathrm{mMFFA}$ and $2 \%$ BSA for $12 \mathrm{~h}$ ); (4) si-MFN2 (cells were transfected with knockdown of MFN2 siRNA for $48 \mathrm{~h}$ and incubated with $2 \%$ BSA for $12 \mathrm{~h}$ ); or (5) si-MFN2+FFA (cells were transfected with knockdown of MFN2 siRNA for $48 \mathrm{~h}$ and treated with $1.2 \mathrm{~m} M$ FFA and $2 \% \mathrm{BSA}$ for $12 \mathrm{~h}$ ). (D) Relative mRNA expression of MFN2 in calf hepatocytes. (E) Western blotting analysis of MFN2. (F) Relative protein expression of MFN2. We used the data from the control group to normalize the data for each treatment group. Treatment of Ad-control had no effect on hepatocytes. Calf hepatocytes were assigned to 1 of 5 treatments: (1) control; (2) Ad-control [cells were transfected with empty adenovirus vector (Ad) for $48 \mathrm{~h}$ and incubated with $2 \%$ BSA for $12 \mathrm{~h}$; ; (3) Ad-control+FFA (cells were transfected with empty adenovirus vector for $48 \mathrm{~h}$ and treated with $1.2 \mathrm{mM}$ FFA and 2\% BSA for $12 \mathrm{~h}$ ); (4) Ad-MFN2 (cells were transfected with MFN2 overexpression adenovirus for $48 \mathrm{~h}$ and incubated with $2 \%$ BSA for $12 \mathrm{~h}$ ); or (5) Ad-MFN2+FFA (cells were transfected with MFN2 overexpression adenovirus and treated with $1.2 \mathrm{mM}$ FFA and $2 \%$ BSA for $12 \mathrm{~h}$ ). Data were analyzed using a priori contrasts: effect of transfection (si/Ad-control vs. control); effect of high FFA (si/Ad-control+FFA vs. si/Ad-control); effect of MFN2 knockdown or overexpression (si/Ad-MFN2 vs. si/Ad-control); effect of MFN2 knockdown at high FFA (si-MFN2+FFA vs. si-control+FFA); and prevention of high FFA effects by MFN2 overexpression (Ad-MFN2+FFA vs. Ad-control+FFA). Results are expressed as mean \pm SEM. $P$-values indicate group differences. Experiments were done in triplicate.

mRNA $-54 \%, P=0.0001 ;$ protein $-34 \%, P<0.0001$ Figure $3 \mathrm{~A}-\mathrm{C})$ and the overexpression experiment (Adcontrol+FFA vs. Ad-control; mRNA $-63 \%, P=0.004$ protein $-58 \%, P=0.0002$; Figure $3 \mathrm{D}-\mathrm{F})$. The same was true for knockdown hepatocytes (si-MFN2+FFA vs. si-MFN2) for MFN2 (mRNA $-36 \%, P=0.04$; protein $-50 \%, P=0.0002$; Figure $3 \mathrm{~A}-\mathrm{C})$ and for overexpressing hepatocytes (Ad-MFN2+FFA vs. Ad-MFN2) at the protein level (protein $-44 \%, P<0.0001$; Figures $3 \mathrm{D}-\mathrm{F})$.

Effect of High FFA and MFN2 Knockdown and Overexpression on the NF- $\kappa B$ Signaling Pathway. The addition of $1.2 \mathrm{~m} M$ FFA (si-control+FFA vs. si-control) increased IKK $\beta$ activity $(+154 \%, P=$ 0.0002 ) and increased the ratios of phosphorylated to nonphosphorylated I $\mathrm{BB} \alpha(+317 \%, P=0.0002)$ and NFкB p65 $(+231 \%, P=0.001)$ in the MFN2 knockdown experiment (Figures $4 \mathrm{~A}-\mathrm{C}$ ). The same was true in the $M F N 2$ overexpression experiment (Ad-control+FFA vs. Ad-control) for IKK $\beta$ activity $(+161 \%, P=0.0004)$ and the ratios of phosphorylated to nonphosphorylated

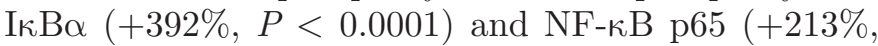
$P<0.0001$; Figures 4D-F). Similar to our findings for high FFA, MFN2 knockdown activated the inflammatory signaling pathway in the absence of high FFA (siMFN2 vs. si-control), as indicated by increased IKK $\beta$ activity $(+120 \%, P=0.001)$ and increased ratios of phosphorylated to nonphosphorylated I $\kappa \mathrm{B} \alpha(+265 \%$,

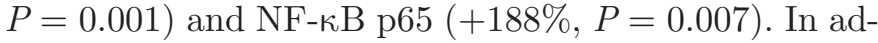
dition, MFN2 knockdown activated the inflammatory 

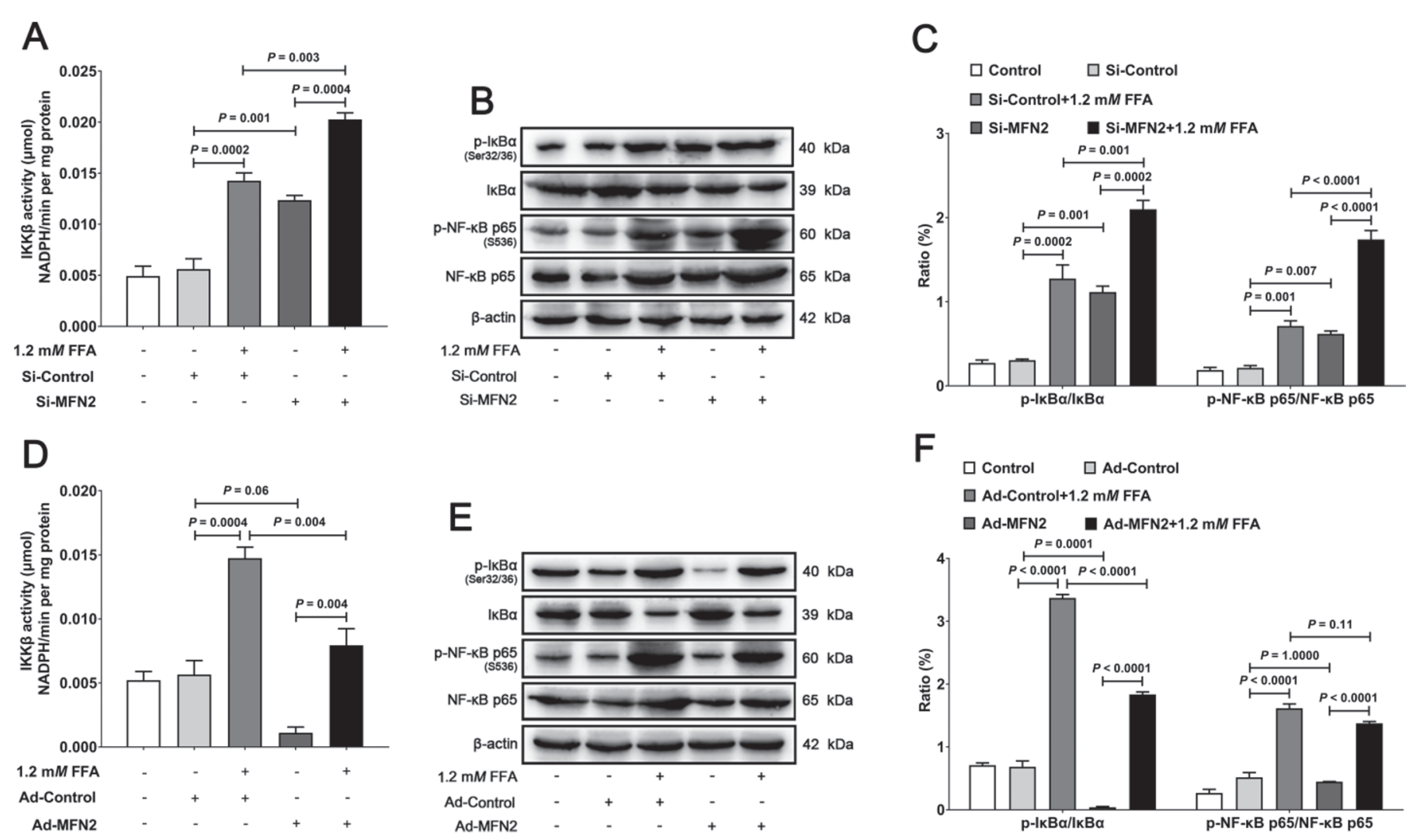

Figure 4. Effect of high free fatty acids (FFA) and mitofusin 2 (MFN2) knockdown and overexpression on the nuclear factor $\kappa \mathrm{B}$ (NF- $\kappa \mathrm{B}$ ) signaling pathway in calf hepatocytes. A detailed description of experimental setup and analysis appears in Figure 3. Panels A to C show the

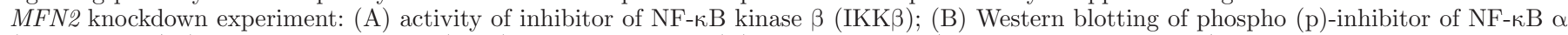

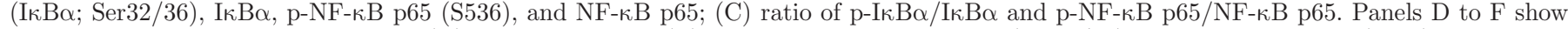

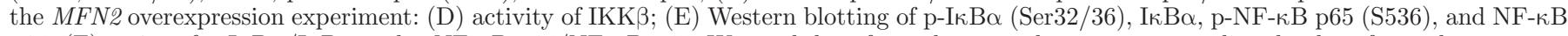
p65; (F) ratios of $\mathrm{p}-\mathrm{I} \kappa \mathrm{B} \alpha / \mathrm{I} \kappa \mathrm{B} \alpha$ and $\mathrm{p}-\mathrm{NF}-\kappa \mathrm{B}$ p65/NF- $\kappa \mathrm{B}$ p65. We used data from the control group to normalize the data for each treatment group. Results are expressed as mean \pm SEM. $P$-values indicate group differences. Experiments were done in triplicate.

pathway in the presence of high FFA (si-MFN2+FFA vs. si-control+FFA), as indicated by increased IKK $\beta$ activity $(+42 \%, P=0.003)$ and increased ratios of phosphorylated to nonphosphorylated I $\kappa \mathrm{B} \alpha(+65 \%, P$

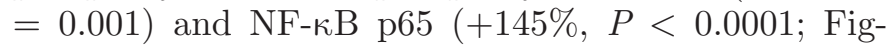
ures $4 \mathrm{~A}-\mathrm{C}$ ). Overexpression of MFN2 partly prevented high-FFA-induced activation of the NF- $\mathrm{BB}$ signaling pathway (Ad-MFN2+FFA vs. Ad-control+FFA), as indicated by decreased $\operatorname{IKK} \beta$ activity $(-46 \%, P=$ $0.004)$ and decreased ratios of phosphorylated to non-

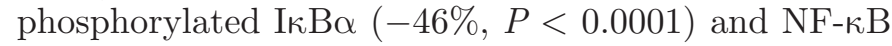
p65 $(-15 \%, P=0.11$; Figure $4 \mathrm{D}-\mathrm{F})$.

Effect of High FFA and MFN2 Knockdown and Overexpression on Inflammasome Signaling Pathway. The addition of $1.2 \mathrm{~m} M$ FFA increased the relative abundance of NLRP3 $(+304 \%, P=0.0001$; Figures 5A and B) and caspase- 1 protein $(+325 \%, P<$ 0.0001; Figures 5A and B) in the MFN2 knockdown experiment (si-control+FFA vs. si-control), and NLRP3 $(+111 \%, P<0.0001$; Figures 5C and D) and caspase-1 protein $(+103 \%, P=0.0001$; Figures $5 \mathrm{C}$ and $\mathrm{D})$ in the $M F N 2$ overexpression experiment (Ad-control+FFA vs. Ad-control). Similar to high FFA, MFN2 knockdown (si-MFN2 vs. si-control ) activated the inflammasome signaling pathway in the absence of FFA (NLRP3 $+192 \%, P=0.003$; caspase- $1+140 \%, P=0.009)$ and in the presence of high FFA (si-MFN2+FFA vs. sicontrol+FFA) as indicated by increased relative abundance of NLRP3 $(+79 \%, P<0.0001$; Figures $5 \mathrm{~A}$ and B) and caspase- $1(+34 \%, P=0.008$; Figures $5 \mathrm{~A}$ and B). Overexpression of MFN2 (Ad-MFN2+FFA vs. Adcontrol+FFA) prevented high FFA-induced activation of the inflammasome signaling pathway, as indicated by a decreased relative abundance of NLRP3 $(-52 \%, P<$ 0.0001 ; Figures 5C and D) and caspase- $1(-78 \%, P<$ 0.0001; Figures 5C and D).

Effect of High FFA and MFN2 Knockdown and Overexpression on Cytokine Gene Expression. The addition of $1.2 \mathrm{~m} M$ FFA increased the relative mRNA abundance of $I L 1 B(+124 \%, P=0.007), I L 6$ 
$(+117 \%, P=0.001)$, and TNFA $(+159 \%, P=0.007)$ in the MFN2 knockdown experiment (si-control+FFA vs. si-control; Figure 6A) and in the MFN2 overexpression experiment (Ad-control+FFA vs. Ad-control; Figure 6B): IL1B $(+102 \%, P=0.003), I L 6(+96 \%, P$ $=0.01)$, and TNFA $(+121 \%, P<0.0001)$. Similar to high FFA, MFN2 knockdown increased cytokine gene expression in the absence of high FFA (si-MFN2 vs. si-control; Figure $6 \mathrm{~A})$ for $\operatorname{IL1B}(+113 \%, P=0.01)$, IL6 $(+101 \%, P=0.004)$, and TNFA $(+119 \%, P=$ 0.05 ), and in the presence of high FFA (si-MFN2+FFA vs. si-control + FFA; Figure $6 \mathrm{~A})$ for $\operatorname{IL1B}(+41 \%, P=$ $0.05), I L 6(+93 \%, P<0.0001)$, and TNFA $(+72 \%, P$ $=0.002$ ). Overexpression of MFN2 (Ad-MFN2+FFA vs. Ad-control+FFA; Figure $6 \mathrm{~B}$ ) prevented a highFFA-induced increase in cytokine gene expression, as indicated by decreased gene expression of $I L 1 B(-43 \%$, $P=0.008)$, IL6 $(-42 \%, P=0.03)$, and TNFA $(-64 \%$, $P<0.0001)$.

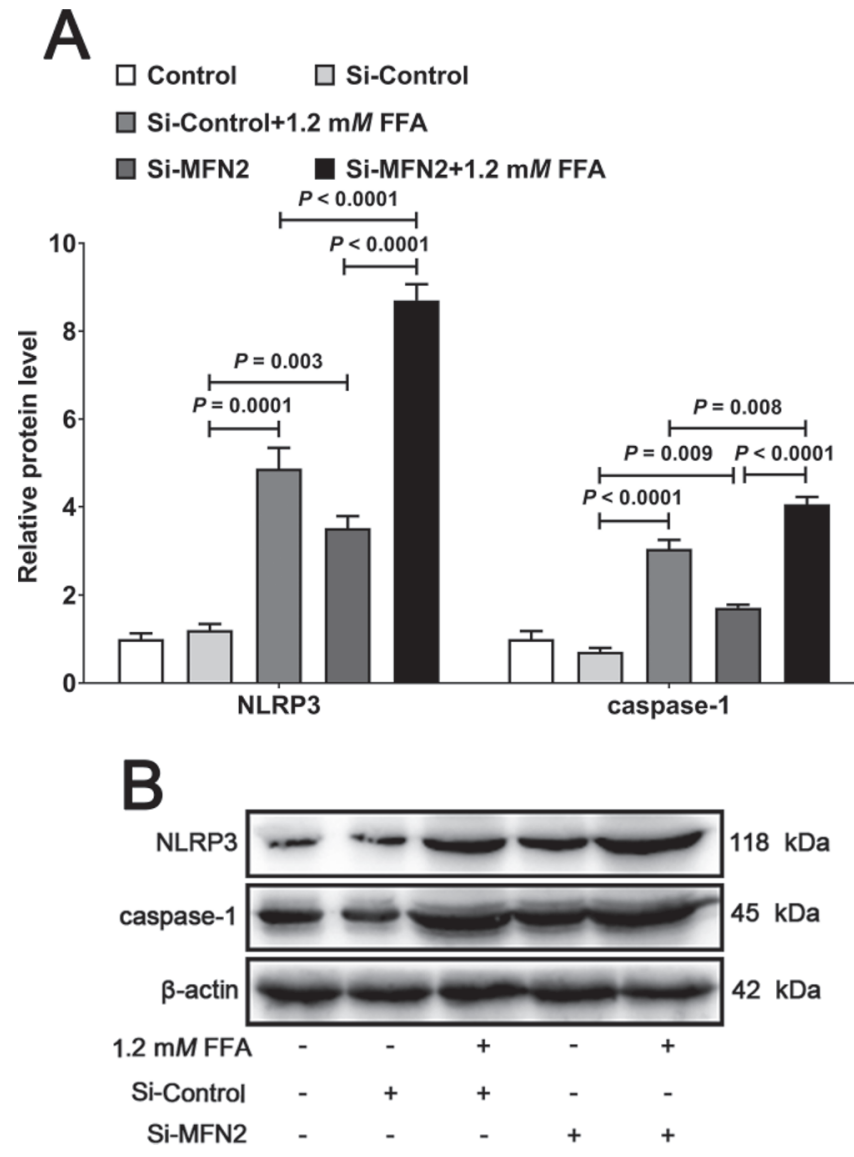

Effect of High FFA and MFN2 Knockdown and Overexpression on Cellular ROS Concentrations. The addition of $1.2 \mathrm{~m} M$ FFA increased cellular ROS concentrations in the MFN2 knockdown experiment (si-control+FFA vs. si-control; $+120 \%, P$ $<0.0001$; Figure 7A) and in the MFN2 overexpression experiment (Ad-control+FFA vs. Ad-control; $+125 \%$, $P<0.0001$; Figure 7B). Similar to high FFA, MFN2 knockdown in the absence of FFA (si-MFN2 vs. sicontrol) increased cellular ROS $(+94 \% ; P=0.0004$ Figure 7A). Overexpression of MFN2 (Ad-MFN2+FFA vs. Ad-control+FFA) prevented the FFA-induced increase in cellular ROS $(-47 \%, P<0.0001$; Figure $7 \mathrm{~B})$.

\section{DISCUSSION}

Most high-yielding dairy cows, specifically overconditioned cows, experience excessive release of FFA from adipose tissue into the circulation during early lacta-

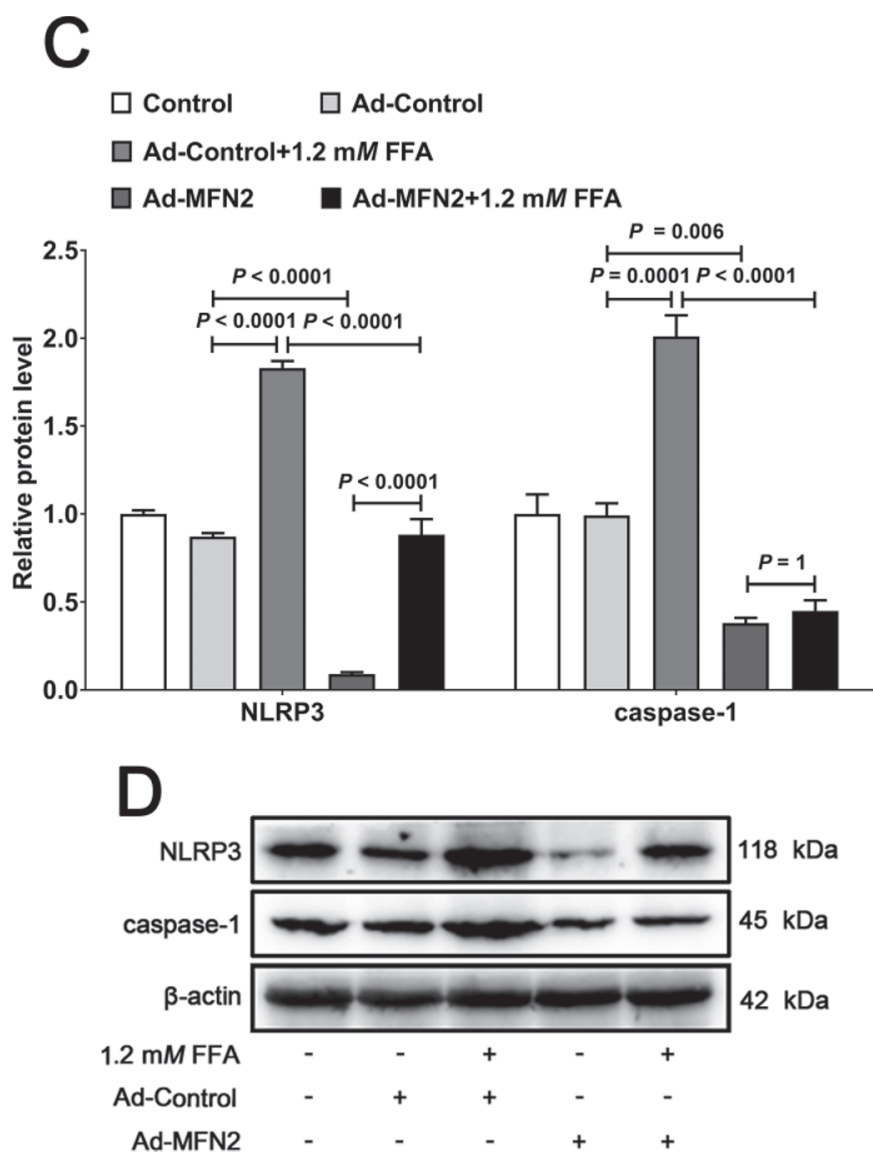

Figure 5. Effect of high free fatty acids (FFA) and mitofusin 2 (MFN2) knockdown and overexpression on the inflammasome signaling pathway in calf hepatocytes. A detailed description of experimental setup and analysis appears in Figure 3. Panels A and B show the MFN2 knockdown experiment: (A) relative protein abundance of NLR family pyrin domain containing 3 (NLRP3) and caspase-1; (B) representative Western blotting of NLRP3 and caspase-1. Panels C and D show the MFN2 overexpression experiment: (C) relative protein abundance of NLRP3 and caspase-1; (D) representative Western blotting of NLRP3 and caspase-1. We used data from the control group to normalize the data for each treatment group. Results are expressed as mean \pm SEM. $P$-values indicate group differences. Experiments were done in triplicate. 

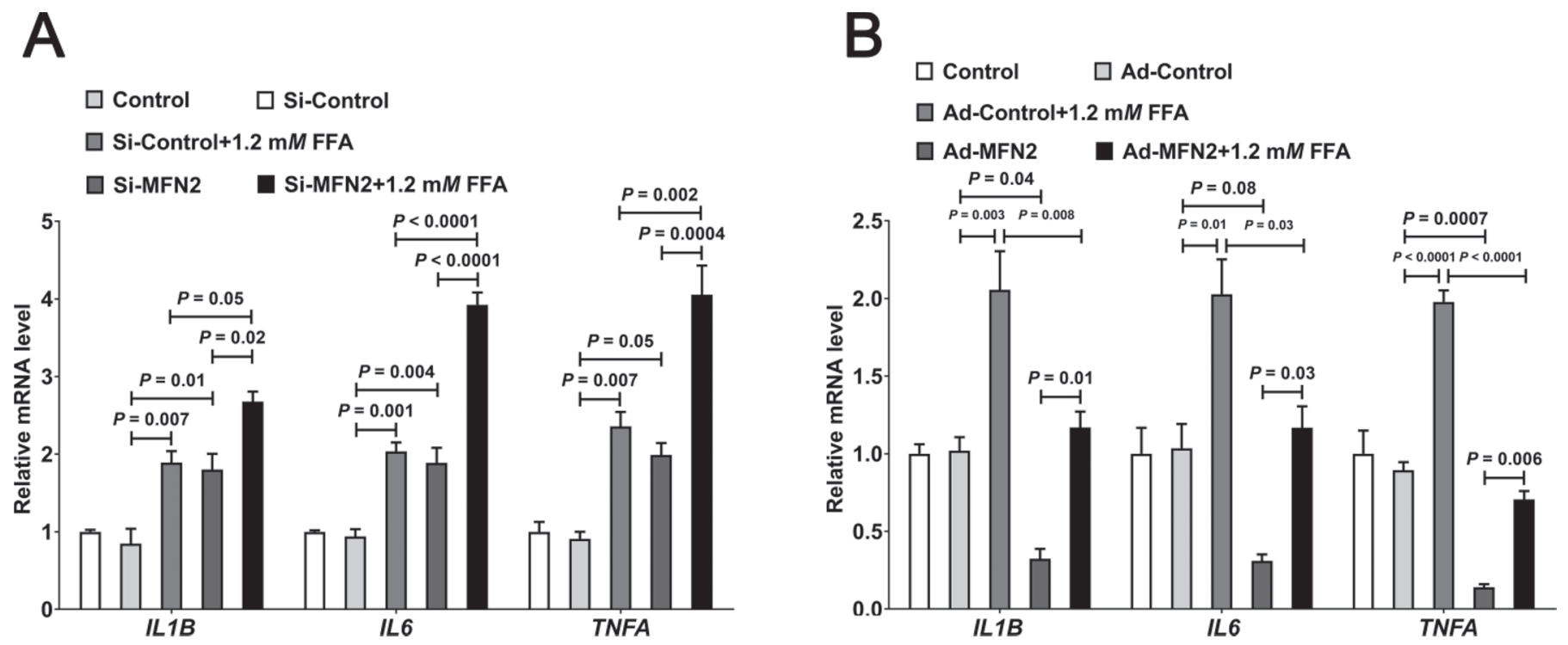

Figure 6. Effect of high free fatty acids (FFA) and mitofusin 2 (MFN2) knockdown and overexpression on cytokine gene expression in calf

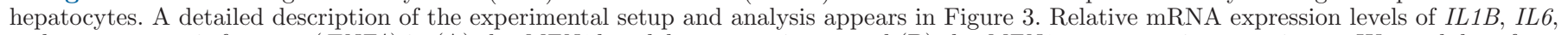
and tumor necrosis factor $\alpha$ (TNFA) in (A) the MFN2 knockdown experiment and (B) the MFN2 overexpression experiment. We used data from

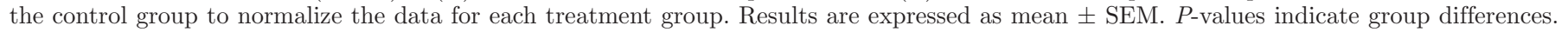
Experiments were done in triplicate.

tion, and these can accumulate in the liver as TAG (Jia et al., 2019). One main finding of this study was that high circulating FFA cause not only TAG accumulation in the liver but also hepatic inflammation. All cows with elevated plasma FFA concentrations had moderate fatty liver and elevated gene expression of cytokines in the liver. In addition, the exposure of healthy calf hepatocytes to high levels of FFA-induced gene expression of cytokines. Previous studies have established a strong association between high circulating FFA concentrations and systemic and hepatic inflammation in dairy cows with moderate and severe fatty liver ( $\mathrm{Li}$ et al., 2015; Shi et al., 2015); this study expanded on those observations and, using a hepatic lipidosis cell culture model, showed that high circulating FFA concentrations induce hepatic inflammation.

How do high circulating FFA concentrations cause hepatic inflammation? Gene expression and synthesis of the inflammatory cytokines IL- $1 \beta$, IL- 6 , and TNF- $\alpha$ are induced by activation of the NF- $\kappa \mathrm{B}$ (Hoesel and Schmid, 2013; Li et al., 2019) and NLRP3 inflammation pathways (Robblee et al., 2016). In this study, all cows with high circulating FFA concentrations had not only elevated hepatic gene expression of $I L 1 B, I L 6$, and TNFA but also activated NF- $\kappa \mathrm{B}$ and NLRP3 inflammation pathways in the liver. Moreover, exposure of healthy calf hepatocytes to high FFA activated the NF$\kappa \mathrm{B}$ and NLRP3 inflammation pathways.

How do high circulating FFA concentrations activate NF- $\kappa$ B and NLRP3 inflammation pathways? Produc- tion of ROS activates NF- $\kappa \mathrm{B}$ and NLRP3 inflammation pathways in the liver (Guo et al., 2014; Cai et al., 2016). In a previous study, we showed that dairy cows with moderate to severe fatty liver had increased ROS release in the liver (Gao et al., 2018). We were able to replicate this association in our cell culture model and showed that the exposure of healthy calf hepatocytes to high levels of FFA-induced ROS release, which in turn activated NF- $\kappa \mathrm{B}$ and NLRP3 inflammation pathways, establishing a connection between high circulating FFA, oxidative stress, and inflammation.

How do high circulating FFA concentrations induce oxidative stress, as indicated by ROS release? Lipid peroxidation is one of the potential pathways by which high circulating FFA concentrations could promote ROS production and activate NF- $\kappa \mathrm{B}$ and NLRP3 inflammation pathways in the liver, and we will examine this pathway in future studies. In the current study, we focused instead on the connection between mitochondrial dysfunction, oxidative stress, and inflammation. Mitochondrial dysfunction activates NF- $\kappa \mathrm{B}$ and NLRP3 inflammation pathways by ROS release (Morgan and Liu, 2011; Jun et al., 2019). As a model for studying mitochondrial dysfunction, we used MFN2, an outer mitochondrial membrane protein that facilitates mitochondrial fusion and is critical for mitochondrial and endoplasmic reticulum function (Rojo et al., 2002; Pich et al., 2005). In mouse liver, low MFN2 causes both mitochondrial dysfunction and ROS release (Sebastián et al., 2012). Moreover, low MFN2 has been 
linked to chronic diseases such as fatty liver, insulin resistance, obesity, cardiomyopathies, cancer, and Alzheimer disease in other species (Gao et al., 2018; Filadi et al., 2018).

In previous studies at dairy farms other than the one used in the current study, we showed that the hepatic abundance of MFN2 was lower in cows with moderate to severe fatty liver (Gao et al., 2018; Dong et al., 2019). We replicated our findings from these studies, because cows with elevated circulating FFA concentrations and moderate fatty liver had lower hepatic MFN2 abundance. Furthermore, we showed in our bovine hepatic lipidosis cell culture model that overexpression of MFN2 prevented FFA-induced decreased mitochondrial function and increased ROS release in calf hepatocytes (Gao et al., 2018). In the current study, we further confirmed and extended those findings. Knockdown of $M F N 2$ increased ROS release and activation of NF- $\mathrm{B}$ and NLRP3 inflammation pathways in calf hepatocytes. Importantly, overexpression of MFN2 prevented the FFA-induced increased ROS release and activation of NF- $\kappa \mathrm{B}$ and NLRP3 inflammation pathways in calf hepatocytes, suggesting that MFN2 could be a therapeutic target for the prevention and treatment of FFAinduced hepatic inflammation in dairy cows during early lactation. Moreover, our findings support a link between elevated circulating FFA concentrations, mitochondrial dysfunction, oxidative stress, and hepatic inflammation in dairy cows during early lactation, as

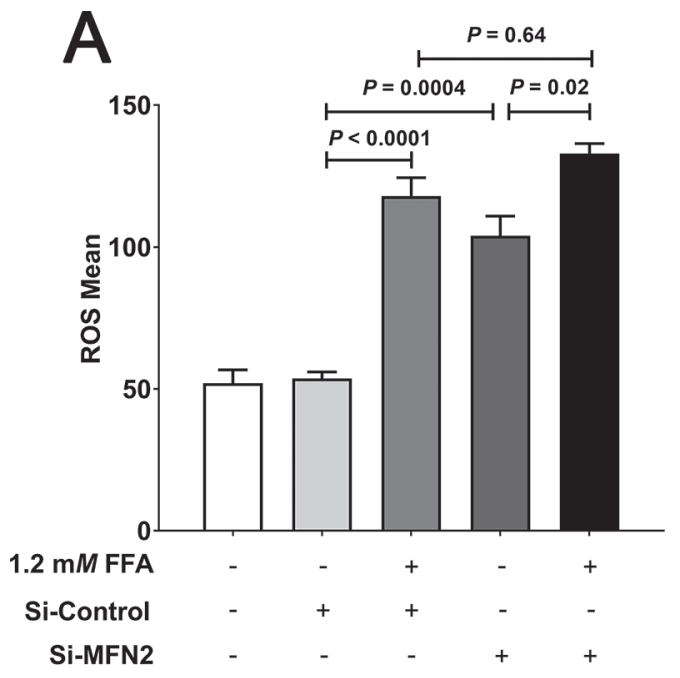

proposed in Figure 8, which will be the focus of our future studies.

\section{CONCLUSIONS}

Most high-yielding-dairy cows - specifically overconditioned cows - experience excessive release of FFA from adipose tissue into the circulation during early lactation. Using cow and cell culture studies, we were able to show that high circulating FFA concentrations caused both hepatic lipidosis and inflammation. We further established a link between high circulating FFA concentrations, mitochondrial dysfunction, oxidative stress, and hepatic inflammation in dairy cows during early lactation. The outer mitochondrial membrane protein MFN2 may be a potential molecular target for the prevention and treatment of FFA-induced hepatic inflammation in dairy cows during early lactation.

\section{ACKNOWLEDGMENTS}

This work was supported by the National Key Research and Development Program (Beijing, China; grant no. 2016YFD0501206), the National Natural Science Foundation of China (Beijing, China; grant no. 31772810), the Natural Science Foundation of Jilin Province (Changchun, China; grant no. 20170101148JC), the Natural Science Scientific Research Project Jointly Established by Jilin University and Jilin Province

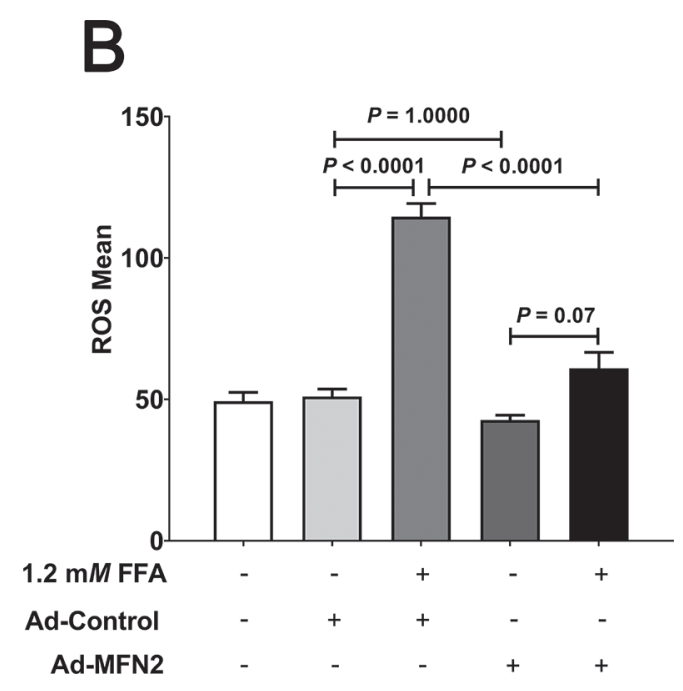

Figure 7. Effect of high free fatty acids (FFA) and mitofusin 2 (MFN2) knockdown and overexpression on reactive oxygen species (ROS) production in calf hepatocytes. A detailed description of the experimental setup and analysis appears in Figure 3. Levels of ROS in (A) the MFN2 knockdown experiment and (B) the MFN2 overexpression experiment. We used data from the control group to normalize the data for each treatment group. Results are expressed as mean \pm SEM. $P$-values indicate group differences. Experiments were done in triplicate. 


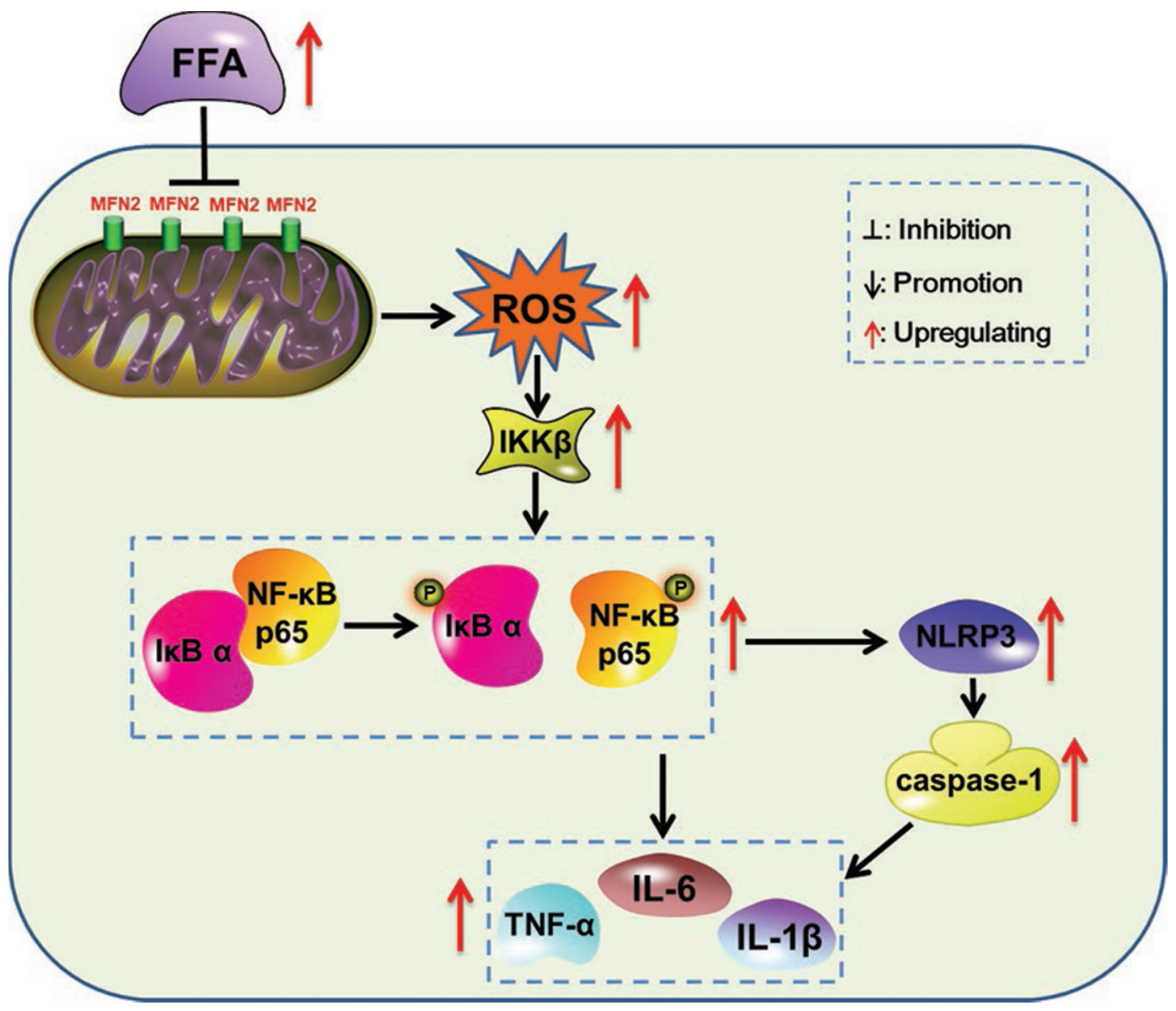

Figure 8. Proposed model of the mechanism that links mitofusin 2 (MFN2) and inflammatory pathways in cows with moderate fatty liver. In dairy cows during early lactation, excessive uptake of free fatty acids (FFA) from adipose tissue by the liver causes mitochondrial damage and release of reactive oxygen species (ROS) into the cytosol, which overactivates the nuclear factor $\kappa B$ (NF- $\kappa B$ ) p65 and NLR family pyrin domain containing 3 (NLRP3) inflammosome signaling pathways, resulting in increased expression and release of proinflammatory cytokines in hepatocytes. Overexpression of MFN2 prevents excessive inflammation in dairy cows during early lactation by preventing mitochondrial damage, ROS release into the cytosol, or both.

(Changchun, China; grant no. SXGJSF2017-6), and the Talents Cultivation Program of Jilin University. The authors have not stated any conflicts of interest.

\section{REFERENCES}

Bobe, G., J. W. Young, and D. C. Beitz. 2004. Invited review: Pathology, etiology, prevention, and treatment of fatty liver in dairy cows. J. Dairy Sci. 87:3105-3124. https://doi.org/10.3168/jds .S0022-0302(04)73446-3.

Brodzki, P., A. Brodzki, L. Krakowski, R. Dabrowski, M. Szczubial, and M. Bochniarz. 2019. Levels of selected cytokines and acutephase proteins in the serum of dairy cows with cystic ovarian disease and those in follicular and luteal phases of normal ovarian cycle. Res. Vet. Sci. 123:20-25. https://doi.org/10.1016/j.rvsc 2018.12.007.

Cai, S. M., R. Q. Yang, Y. Li, Z. W. Ning, L. L. Zhang, G. S. Zhou, W. Luo, D. H. Li, Y. Chen, M. X. Pan, and X. Li. 2016. Angiotensin-(1-7) improves liver fibrosis by regulating the NLRP3 inflammasome via redox balance modulation. Antioxid. Redox Signal. 24:795-812. https://doi.org/10.1089/ars.2015.6498.
Catrysse, L., and G. van Loo. 2017. Inflammation and the metabolic syndrome: The tissue-specific functions of NF-kappaB. Trends Cell Biol. 27:417-429. https://doi.org/10.1016/j.tcb.2017.01.006.

Cui, Y., Q. Wang, R. Chang, X. Zhou, and C. Xu. 2019. Intestinal barrier function-non-alcoholic fatty liver disease interactions and possible role of gut microbiota. J. Agric. Food Chem. 67:2754-2762. https://doi.org/10.1021/acs.jafc.9b00080.

Dong, J., J. J. Loor, R. Zuo, X. Chen, Y. Liang, Y. Wang, X. Shu, X. Sun, H. Jia, G. Liu, Z. Wang, X. Li, and X. Li. 2019. Low abundance of mitofusin 2 in dairy cows with moderate fatty liver is associated with alterations in hepatic lipid metabolism. J. Dairy Sci. 102:7536-7547. https://doi.org/10.3168/jds.2019-16544.

Du, X., T. Shen, H. Wang, X. Qin, D. Xing, Q. Ye, Z. Shi, Z. Fang, Y. Zhu, Y. Yang, Z. Peng, C. Zhao, B. Lv, X. Li, G. Liu, and X. Li. 2018a. Adaptations of hepatic lipid metabolism and mitochondria in dairy cows with mild fatty liver. J. Dairy Sci. 101:9544-9558.

Du, X., Y. Zhu, Z. Peng, Y. Cui, Q. Zhang, Z. Shi, Y. Guan, X. Sha, T. Shen, Y. Yang, X. Li, Z. Wang, X. Li, and G. Liu. 2018b. High concentrations of fatty acids and beta-hydroxybutyrate impair the growth hormone-mediated hepatic JAK2-STAT5 pathway in clinically ketotic cows. J. Dairy Sci. 101:3476-3487. https://doi.org/10 $.3168 /$ jds.2017-13234. 
Farke, C., H. H. Meyer, R. M. Bruckmaier, and C. Albrecht. 2008. Differential expression of $\mathrm{ABC}$ transporters and their regulatory genes during lactation and dry period in bovine mammary tissue. J. Dairy Res. 75:406-414. https://doi.org/10.1017/ S002202990800335X.

Filadi, R., E. Greotti, and P. Pizzo. 2018. Highlighting the endoplasmic reticulum-mitochondria connection: Focus on Mitofusin 2. Pharmacol. Res. 128:42-51. https://doi.org/10.1016/j.phrs.2018 .01 .003 .

Gao, W., X. Du, L. Lei, H. Wang, M. Zhang, Z. Wang, X. Li, G. Liu, and X. Li. 2018. NEFA-induced ROS impaired insulin signalling through the JNK and p38MAPK pathways in non-alcoholic steatohepatitis. J. Cell. Mol. Med. 22:3408-3422. https://doi.org/10 $.1111 / \mathrm{jcmm} .13617$.

German, A. J., V. H. Ryan, A. C. German, I. S. Wood, and P. Trayhurn. 2010. Obesity, its associated disorders and the role of inflammatory adipokines in companion animals. Vet. J. 185:4-9. https:/ /doi.org/10.1016/j.tvjl.2010.04.004.

Guo, Y., Y. Zhang, K. Hong, F. Luo, Q. Gu, N. Lu, and A. Bai. 2014. AMPK inhibition blocks ROS-NFkB signaling and attenuates endotoxemia-induced liver injury. PLoS One 9:e86881. https: //doi.org/10.1371/journal.pone.0086881.

Hoesel, B., and J. A. Schmid. 2013. The complexity of NF-kappaB signaling in inflammation and cancer. Mol. Cancer 12:86. https:// doi.org/10.1186/1476-4598-12-86.

Jia, H., X. Li, G. Liu, J. J. Loor, R. Bucktrout, X. Sun, G. Li, X. Shu, J. Dong, Y. Wang, R. Zuo, Z. Wang, and X. Li. 2019. Perilipin 5 promotes hepatic steatosis in dairy cows through increasing lipid synthesis and decreasing very-low-density lipoprotein assembly. J. Dairy Sci. 102:833-845. https://doi.org/10.3168/jds.2018-15208.

Jun, J. H., J. K. Shim, J. E. Oh, E. J. Shin, E. Shin, and Y. L. Kwak. 2019. Protective effect of ethyl pyruvate against myocardial ischemia reperfusion injury through regulations of ROS-related NLRP3 inflammasome activation. Oxid. Med. Cell. Longev. 2019:4264580. https://doi.org/10.1155/2019/4264580.

Kuang, J., M. Xie, and X. L. Wei. 2018. The NALP3 inflammasome is required for collagen synthesis via the NF- $\kappa \mathrm{B}$ pathway. Int. J. Mol. Med. 41:2279-2287. https://doi.org/10.3892/ijmm.2018.3404.

Lebeaupin, C., E. Proics, C. H. de Bieville, D. Rousseau, S. Bonnafous, S. Patouraux, G. Adam, V. J. Lavallard, C. Rovere, O. Le Thuc, M. C. Saint-Paul, R. Anty, A. S. Schneck, A. Iannelli, J. Gugenheim, A. Tran, P. Gual, and B. Bailly-Maitre. 2015. ER stress induces NLRP3 inflammasome activation and hepatocyte death. Cell Death Dis. 6:e1879. https://doi.org/10.1038/cddis.2015.248.

Li, J., X. Zheng, X. Ma, X. Xu, Y. Du, Q. Lv, X. Li, Y. Wu, H. Sun, L. Yu, and Z. Zhang. 2019. Melatonin protects against chromium(VI)-induced cardiac injury via activating the AMPK/ Nrf2 pathway. J. Inorg. Biochem. 197:110698. https://doi.org/10 .1016/j.jinorgbio.2019.110698.

Li, X., W. Huang, J. Gu, X. Du, L. Lei, X. Yuan, G. Sun, Z. Wang, X. $\mathrm{Li}$, and G. Liu. 2015. SREBP-1c overactivates ROS-mediated hepatic NF-kappaB inflammatory pathway in dairy cows with fatty liver. Cell. Signal. 27:2099-2109. https://doi.org/10.1016/j.cellsig 2015.07.011.

Morgan, M. J., and Z. G. Liu. 2011. Crosstalk of reactive oxygen species and NF-kappaB signaling. Cell Res. 21:103-115. https://doi .org/10.1038/cr.2010.178.

Parker, J. E., and E. M. Gaughan. 1988. Partial hepatic resection for treatment of a single liver abscess in a dairy heifer. Vet. Surg. 17:87-89. https://doi.org/10.1111/j.1532-950X.1988.tb00283.x.
Pich, S., D. Bach, P. Briones, M. Liesa, M. Camps, X. Testar, M. Palacin, and A. Zorzano. 2005. The Charcot-Marie-Tooth type 2A gene product, Mfn2, up-regulates fuel oxidation through expression of OXPHOS system. Hum. Mol. Genet. 14:1405-1415. https://doi .org $/ 10.1093 / \mathrm{hmg} / \mathrm{ddi} 149$

Robblee, M. M., C. C. Kim, J. P. Abate, M. Valdearcos, K. L. M. Sandlund, M. K. Shenoy, R. Volmer, T. Iwawaki, and S. K. Koliwad. 2016. Saturated fatty acids engage an IRE1alpha-dependent pathway to activate the NLRP3 inflammasome in myeloid cells. Cell Rep. 14:2611-2623. https://doi.org/10.1016/j.celrep.2016.02 .053 .

Rojo, M., F. Legros, D. Chateau, and A. Lombes. 2002. Membrane topology and mitochondrial targeting of mitofusins, ubiquitous mammalian homologs of the transmembrane GTPase Fzo. J. Cell Sci. 115:1663-1674.

Sebastián, D., M. I. Hernández-Alvarez, J. Segalés, E. Soríanello, J. P. Munoz, D. Sala, A. Waget, M. Líesa, J. C. Paz, P. Gopalacharyulu, M. Oresic, S. Pich, R. Burcelin, M. Palacín, and A. Zorzano. 2012. Mitofusin 2 (Mfn2) links mitochondrial and endoplasmic reticulum function with insulin signaling and is essential for normal glucose homeostasis. Proc. Natl. Acad. Sci. USA 109:5523-5528. https:// doi.org/10.1073/pnas.1108220109.

Shen, T., X. Li, J. J. Loor, Y. Zhu, X. Du, X. Wang, D. Xing, Z. Shi, Z. Fang, X. Li, and G. Liu. 2019. Hepatic nuclear factor kappa B signaling pathway and NLR family pyrin domain containing 3 inflammasome is over-activated in ketotic dairy cows. J. Dairy Sci. 102:10554-10563. https://doi.org/10.3168/jds.2019-16706.

Shi, X., D. Li, Q. Deng, Y. Li, G. Sun, X. Yuan, Y. Song, Z. Wang, X. Li, X. Li, and G. Liu. 2015. NEFAs activate the oxidative stressmediated NF-kappaB signaling pathway to induce inflammatory response in calf hepatocytes. J. Steroid Biochem. Mol. Biol. 145:103-112. https://doi.org/10.1016/j.jsbmb.2014.10.014.

Trayhurn, P., and I. S. Wood. 2004. Adipokines: Inflammation and the pleiotropic role of white adipose tissue. Br. J. Nutr. 92:347-355. https://doi.org/10.1079/BJN20041213.

Yang, G., H. E. Lee, and J. Y. Lee. 2016. A pharmacological inhibitor of NLRP3 inflammasome prevents non-alcoholic fatty liver disease in a mouse model induced by high fat diet. Sci. Rep. 6:26218. https://doi.org/10.1038/srep26218.

Yang, X., X. Zhang, J. Zhang, Q. Ji, W. Huang, X. Zhang, and Y. Li. 2019. Spermatogenesis disorder caused by T-2 toxin is associated with germ cell apoptosis mediated by oxidative stress. Environ. Pollut. 251:372-379. https://doi.org/10.1016/j.envpol.2019.05.023.

Zhao, X. J., Z. P. Li, J. H. Wang, X. M. Xing, Z. Y. Wang, L. Wang, and Z. H. Wang. 2015. Effects of chelated $\mathrm{Zn} / \mathrm{Cu} / \mathrm{Mn}$ on redox status, immune responses and hoof health in lactating Holstein cows. J. Vet. Sci. 16:439-446.

Zhu, Y., Y. Guan, J. J. Loor, X. Sha, D. N. Coleman, C. Zhang, X. Du, Z. Shi, X. Li, Z. Wang, G. Liu, and X. Li. 2019. Fatty acidinduced endoplasmic reticulum stress promoted lipid accumulation in calf hepatocytes, and endoplasmic reticulum stress existed in the liver of severe fatty liver cows. J. Dairy Sci. 102:7359-7370. https://doi.org/10.3168/jds.2018-16015.

\section{ORCIDS}

Gerd Bobe ๑ https://orcid.org/0000-0002-3129-5628

Xinwei Li ๑ https://orcid.org/0000-0002-0765-677X 